Discussion Paper Series A No.487

\title{
Endogenous Relationship Banking to Alleviate Excessive Screening Transaction Banking
}

Yoshiaki Ogura

December 2006

The Institute of Economic Research Hitotsubashi University

Kunitachi, Tokyo, 186-8603 Japan 


\title{
Endogenous Relationship Banking to Alleviate Excessive Screening in Transaction Banking*
}

\author{
Yoshiaki Ogura
}

\author{
Institute of Economic Research \\ Hitotsubashi University \\ 2-1 Naka, Kunitachi \\ Tokyo, 186-8603, Japan \\ E-mail: ogura@ier.hit-u.ac.jp
}

December 2006

\footnotetext{
*I am grateful to my advisers Lee Branstetter, Eslyn Jean-Baptiste, and especially Michael Riordan for precious guidance and support. This paper is based on a chapter in my Ph.D. dissertation at Columbia University. I also thank Kenn Ariga, Kyle Bagwell, Dirk Bergemann, Makoto Saito, Raphael Thomadsen, and the participants in seminars at Columbia University, Hitotsubashi University, Institute for Monetary and Economic Research at the Bank of Japan, Osaka University, Tohoku University, and Waseda University for valuable comments. I am fully responsible for all remaining errors.
} 


\begin{abstract}
This paper analyzes how learning a borrower's creditworthiness, from past lending decision by a rival bank that is publicly observable through private or public credit reporting systems, affects the performance of subsequent lending competitions. Our analysis of twicerepeated lending competitions demonstrates that such ex post information sharing causes inefficient and excessive screening of new borrowers when banks undertake transaction banking since each bank expects future disadvantages to result from the information revelation. Relationship banking arises endogenously as a defense against such anticipated disadvantage, and improves the economic efficiency by alleviating the excessive screening.
\end{abstract}

JEL Classifications: G21 L14

Keywords: relationship banking, informational externality, interbank competition, commonvalue repeated auction 


\section{Introduction}

A credit market plays an important role in the allocation of resources and determining a level of activity in an economy by generating credit through interbank competition. While making loan decisions, banks assess the creditworthiness of borrowers, or their ability to repay loans, in order to maximize profits, considering the high returns on risky loans. In their assessments, banks need to collect all available information and make the best use of it. Therefore, the economic efficiency of the banking sector depends on how well each bank collects information and incorporate that information into its lending decisions. If banks are repeatedly competing to extend loans to a firm, the available information about that firm should include information about past lending decisions made by the rival banks. This information; typically available through public or private credit reporting systems, reveals these banks' private evaluations of the creditworthiness of the company. This learning by rivals, in turn, affects the level of effort made by the incumbent lender to acquire company-specific soft information covering, for instance, management ability, potential profit opportunities for original technology, or skills within the borrowing firm. In the existing banking literature, however, the dynamic effects of these learning processes among the rival banks on the performance of the lending market, including information production and credit availability, have not yet been fully analyzed. The present study attempts to fill this void in the literature.

In the received literature, banking activities fall into two categories: relationship banking and transaction banking. Relationship banking has been defined, for example, by Boot [4], as financial intermediation provided by an institution that "(1) invests in obtaining customerspecific information, often proprietary in nature and (2) evaluates the profitability of these investments through multiple interactions with the same customer over time and/or across products." Transaction banking "focuses on a single transaction with a customer." This paper follows these definitions.

First, the present study shows that the rival bank's learning from the past lending decisions renders the screening of new borrowers stricter than the socially optimal level (excessive screen- 
ing) when banks undertake transaction banking, since each bank expects future disadvantages to result from the private information revealed by winning and reporting a loan contract to a credit reporting system. In fact, it can be shown that a bank expects, at most, zero profit from future competition when it wins the first competition under these conditions. This is because a rival bank can take advantage of the winning bank's private information about the borrower. In addition, the rival becomes more optimistic about the creditworthiness of the borrower by examining the revealed private information that is most optimistic among the competing banks, while the incumbent lender becomes more pessimistic because it learns that its rival has private information, rendering it less optimistic (winner's curse, Broecker [7], Riordan [30], and Shaffer [32]). Based on these posterior beliefs, the rival offers an interest rate at which the incumbent lender cannot earn a positive profit in the next lending competition. Thus, the return for the incumbent lender from future lending competitions is always zero even if the first lending decision made by the incumbent lender could have positive impact on the social welfare by enhancing credit availability in future. This discrepancy between the competitive profit for the incumbent lender and the social return from the first lending decision results in excessive screening by banks in the first lending competition.

Second, the present study shows that relationship banking arises endogenously as a defense by an incumbent lender against future aggression from a rival bank, as mentioned in the previous paragraph. In response to aggression by other banks, the incumbent lender attempts to ensure a positive return in the future by collecting additional soft information that the other banks cannot obtain. The anticipated positive return from the customer relationship in the future relaxes the creditworthiness test for new borrowers during the first lending decision. Thus, endogenous relationship banking alleviates the welfare loss caused by excessive screening. Those who cannot start a business under transaction banking can do so by eliciting relationship banking, although the interest rate may be higher than that under transaction banking.

In the existing literature, relationship banking is considered as a device to alleviate the entrepreneur's moral hazard, using the threat of loan termination should they fail (Bolton and Sharfstein [3], Stiglitz and Weiss [35]), and the reward of an interest rate discount should they 
succeed (Boot and Thakor [5]). ${ }^{1}$ However, relationship banking allows the incumbent lender to enjoy an information advantage over the rival banks and gives it a chance to exploit partial monopolistic rents in the future (Sharpe [33]) or to deter entry by rival banks (Dell'Ariccia, Friedman, and Marquez [10]). This exploitation discourages entrepreneurs from making proper management efforts (Rajan [29]) and causes an over-lending problem for less creditworthy companies (Sharpe [33]). Thus, the existing literature seems to conclude that the acquisition of proprietary information, which accompanies relationship banking, is socially undesirable and should be avoided. In contrast, the present study outlines the possibility that the rent resulting from such information acquisition drives banks to undertake relationship banking and improves welfare by alleviating the excessive screening problem, which is inherent in transaction banking in a market with a sophisticated credit reporting system. Several studies have formulated relationship banking as a strategic information acquisition in a static framework (Schnitzer [31], Hauswald and Marquez [20]). For example, Hauswald and Marquez [20] show that banks tend to overinvest in information acquisition in a static, localized oligopoly framework. The present study shows another welfare implication of strategic information acquisition in a dynamic framework. $^{2}$

The key assumption in this paper is the ex post public observability of the private information underlying the past lending decision by an incumbent lender. One or more public or private credit reporting systems are operating in many countries. ${ }^{3}$ In these systems, lenders

\footnotetext{
${ }^{1}$ In this context, von Thadden [37] characterizes an optimal long-term contract with monitoring as a device to encourage entrepreneurs to take on long-term projects rather than less profitable short-term projects using the "rescue" promise from a relational bank. As to the empirical examinations, the existing literature shows mixed results. Berger and Udell [2] found that interest rate costs on credit-line contracts decrease with the length of the relationship. In contrast, Petersen and Rajan [28] found no significant correlation between interest costs and the length of the relationship, whereas Degryse and Cayseele [9] found a positive correlation between them. Weinstein and Yafeh [38] found from Japanese data that the relationship had a negative effect on the performance of borrowing companies. A study by Miwa and Ramseyer [26] also showed that the moral hazard story is not supported by the data in Japan.

${ }^{2}$ In another line of research, relationship banking is considered as "product differentiation" by banks. Boot and Thakor [6], and Yafeh and Yosha [40] demonstrated the possibility that increased competitive pressure from rival banks in transaction banking invokes an incentive for each bank to invest in improving its consulting ability to enhance customer profitability in a certain segment of the market, and this results in relationship banking. Dinç [12] shows that competitive pressure from the rival banks generates an incentive to differentiate oneself from the rivals by establishing a reputation for being sure to help borrowers who are temporarily distressed.

${ }^{3}$ See Jappelli and Pagano [22], and Miller [25] for details.
} 
supply a credit bureau with data about their customers and the terms of extended loans. The bureau compiles the information and provides credit reports to the lenders participating in the reporting system. Thus, credit reporting systems facilitate information sharing among lenders that is ex post in the sense that credit information is exchanged only after a bank or a supplier has extended a loan to the borrower. Jappelli and Pagano [22] show that private credit bureaus tend to provide more detailed information, including the terms of each loan contract and the borrower's credit history and financial statements, from which banks can directly or indirectly infer the incumbent lender's private information about the creditworthiness of the borrower. On this point, the propositions in this paper are applicable to credit markets where such sophisticated credit bureaus facilitate ex post information sharing. A seminal paper by Jappelli and Pagano [21] demonstrates the possibility that information sharing enhances credit availability for informationally opaque firms, and another paper by Jappelli and Pagano [22] empirically verifies this proposition with the dataset collected from 40 countries. The present study shows that the public observability of the private evaluation underlying the past lending decision by an incumbent lender, indeed, enhances the credit availability in future lending competition; however, there is still room to improve the economic efficiency by solving the excess screening problem that emerges from the first lender's dynamic consideration.

The model is formulated as twice-repeated first-price common-value auctions under multiunit demand. Several studies have analyzed equilibrium bids, payoffs, and the effects of learning from the rival bids on equilibrium bidding behavior (Ortega-Reihert [27], Hausch [18, 19], and Engelbrecht-Wiggans and Weber [13]). However, the welfare impact of this learning when a reservation value exists has not yet been analyzed by the existing literature. The present study illustrates the welfare consequences of learning from the past lending decision by a rival under the assumptions that the winner's private signal is publicly observable ex post while the loser's bid is not, and that the expected profitability of each loan to a firm is identical not only stochastically but also "informationally" in the sense that the private signal that each bank acquires prior to the initial bid is time-invariant without additional information acquisition.

The remainder of this paper is organized as follows. Section 2 describes the basic structure of 
the model. Section 3 derives the equilibrium in a twice-repeated competition under transaction banking and illustrates the excessive screening problem. Section 4 illustrates the equilibrium in a twice-repeated competition under relationship banking and shows how it alleviates the excessive screening problem. Conclusions are presented in Section 5. All proofs are given in the appendix.

\section{The Model}

At Date 1, a firm that plans to begin a project that costs $I$ applies to two banks for a loan. It is assumed that the only available financial resource for the firm is a bank lending. The financing cost of each bank is assumed to be zero. If it is a good firm $(G)$, the revenue from the project will always be equal to $V(>I)$. If it is a bad firm $(B)$, the revenue will always be equal to 0 . It is assumed that neither the banks nor the firm knows the exact type of the firm for the time being. Each bank competitively offers a gross interest rate $R_{1}$. The firm then chooses a bank offering the lowest rate. It is assumed that the banks compete via a first-price sealed-bid auction. $^{4}$

The revenue from this project is realized two periods later, at Date 3. The firm repays the first loan on this date. Before then, at Date 2, the firm needs to apply for another loan to finance the additional cost $I$ to continue the project (Figure 1). ${ }^{5}$ A firm that was unable to obtain a loan at Date 1 reapplies at Date 2. The banks compete once again at Date 2. The revenue from this continuation is realized at Date 4 .

The loan considered is a standard debt contract, which is derived as an optimal contract under the assumption that realized revenue is an entrepreneur's private information and is verifiable to a lender only by costly state verification (Townsend [36], Gale and Hellwig [16], and

\footnotetext{
${ }^{4}$ Firms may convert an interbank competition into an English auction by revealing the offer made by one bank to its rival as part of the search for the best deal. However, banks cannot accept a statement by a potential borrower concerning a rival bid, since the firm always has an incentive to claim falsely low interest rates to a rival bank in order to make it more aggressive. Therefore, a sealed-bid auction is more appropriate than an open-bid auction in this context.

${ }^{5}$ Some readers may feel uncomfortable about this assumption since most small companies take out an additional loan only after they successfully repay a previous loan in full. If it is assumed that there is a certain probability that a bad firm can make a profit by accident, a similar analysis can be undertaken even if it is assumed that a firm applies for another loan after successfully repaying the previous loan, except that we need to consider the additional step of Bayesian learning from a successful repayment. In order to keep notations to a minimum, we assume the environment to be as stated in the text.
} 
Williamson [39]). The return for the bank from the loan is $\min [v, R]-I$, where $R$ is the gross interest rate and $v$ is equal to $V$ if the firm is good or 0 if it is bad. The payoff for the firm is residual after the repayment: $\max [0, v-R]$. The firm always has an incentive to apply for a loan since it can earn a profit in any case owing to the limited liability of the standard debt contract.

Each bank knows that the ratio of good companies in the economy is $\gamma$, and that the remainder, $1-\gamma$, is the ratio of bad companies. Upon receiving a loan application at Date 1 , Bank $i(i=1,2)$ obtains a private signal $s_{i} \in[\underline{s}, \bar{s}]$ about the quality of the firm at no cost. $s_{i}$ is a random draw from a cumulative distribution function $F\left(s_{i} \mid\right.$ type $)$ given that type $=G$ or $B$. It is assumed that $s_{i}$ is independently and identically distributed, conditional on the type of firm. The corresponding probability distribution function is denoted by $f\left(s_{i} \mid\right.$ type $)$, which is assumed positive for any $s_{i} \in[\underline{s}, \bar{s}]$. A signal $s_{i}$ represents private information that Bank $i$ acquires through a preliminary creditworthiness test. Two standard assumptions about the distribution function of the signal are made as

$$
\begin{aligned}
\frac{d}{d s_{i}} \frac{f\left(s_{i} \mid G\right)}{f\left(s_{i} \mid B\right)} & >0 \quad \text { (likelihood ratio dominance) } \\
\frac{d}{d s_{i}} \frac{f\left(s_{i} \mid \text { type }\right)}{F\left(s_{i} \mid \text { type }\right)} & <0, \quad \text { type }=G, B \quad \text { (log concavity). }
\end{aligned}
$$

It is well known that the likelihood ratio dominance (1) implies ${ }^{6}$

$$
\begin{aligned}
F\left(s_{i} \mid G\right)<F\left(s_{i} \mid B\right) \quad \text { (first order stochastic dominance) } \\
\frac{f\left(s_{i} \mid G\right)}{F\left(s_{i} \mid G\right)}>\frac{f\left(s_{i} \mid B\right)}{F\left(s_{i} \mid B\right)} \quad \text { (reverse hazard rate dominance) }
\end{aligned}
$$

The first order stochastic dominance (3) means that a bank is more likely to obtain a higher signal if the firm is $G$.

After obtaining a signal from the first competition, each bank updates its belief about the type of the borrower in a Bayesian manner. At this stage, Bank $i$ believes that the potential borrower is $G$ with a probability of

$$
\mu\left(s_{i}\right)=\frac{\gamma f\left(s_{i} \mid G\right)}{\gamma f\left(s_{i} \mid G\right)+(1-\gamma) f\left(s_{i} \mid B\right)} .
$$

${ }^{6}$ For example, see Appendix B in Krishna [23]. 


\begin{tabular}{|c|c|c|c|}
\hline Date 1 & Date 2 & Date 3 & Date 4 \\
\hline Firm applies for a loan. & \multirow{2}{*}{$\begin{array}{l}\text { Firm applies } \\
\quad \text { for another loan. }\end{array}$} & First revenue. & Second revenue. \\
\hline Banks get signal $s_{i}$. & & First repayment. & Second repayment. \\
\hline First bidding $R_{1}\left(s_{i}\right)$. & Rival observes $w$. & & \\
\hline Loan. & Second bidding. & & \\
\hline Firm invests. & Loan. & & \\
\hline & Firm continues operatior & & \\
\hline
\end{tabular}

Figure 1: Flow of the Game

Based on this posterior belief, each bank offers a gross interest rate $R_{1}\left(s_{i}\right)$.

At Date 2, it is assumed that a private or public credit reporting system is so sophisticated that each bank can observe whether the firm obtained a loan, and if so, it can also observe the first lender's private signal $w$. The robustness of the propositions will be checked against other assumptions regarding the observability of past lending decisions by a rival in Section 3.4. It is assumed that the winner in the first competition wins again if two bids tie in the second competition. It is also assumed that the winning bank in each competition sets an early repayment charge that is high enough to deter the borrower from refinancing via a rival bank before the loan reaches maturity. Figure 1 summarizes the flow of the game.

\section{Transaction Banking}

Under transaction banking, a bank does not collect proprietary information about the borrower after winning a loan contract at Date 1 (Boot [4]). A perfect Bayesian equilibrium in the twice-repeated competition under transaction banking is derived backward.

\subsection{Second Competition}

The winner in the first competition is termed Bank $W$, and the loser is termed Bank $L$. If each bank bids according to the monotone strategy in the first competition, as we will show in the 
next section, there will be two outcomes regarding the information environment in the second competition. (1) If a bank extended a loan in the equilibrium in the first competition, then the private signal of Bank $W$, which is denoted by $w$, is available as additional public information through a credit reporting system. (2) If neither bank extended a loan in the first competition, the additional information for each bank comprises the fact that each private signal is lower than the screening threshold $s_{* 1}^{t}$ in the first competition; this will be derived in the next section. The equilibrium strategies in these two cases are derived below.

\section{(1) Case 1: Bank W extended a loan under the equilibrium in the first competition at the interest rate of $R_{1}(w)$.}

The fact that Bank $W$ won in the first competition implies that the private signal of Bank $L$ is lower than $w$. Therefore, Bank $W$ believes that the borrower is a good firm with a probability of $^{7}$

$$
\nu_{w}(w)=\frac{\mu(w) F(w \mid G)}{\mu(w) F(w \mid G)+(1-\mu(w)) F(w \mid B)} .
$$

In contrast, Bank $L$ exactly knows that the highest realized private signal is $w$. The posterior belief of Bank $L$ is

$$
\nu_{l}(l, w)=\frac{\mu(l) f(w \mid G)}{\mu(l) f(w \mid G)+(1-\mu(l)) f(w \mid B)} .
$$

$l$ is the private signal that Bank $L$ receives at Date 1.

In the second competition, Bank $W$ adopts a mixed strategy that follows a cumulative distribution function $G\left(R_{w}\right)$, where $R_{w}$ is the interest rate offered by Bank $W$. The corresponding probability distribution function is denoted by $g\left(R_{w}\right)$. Bank $W$ participates in the competition with probability $q$. The bid function of Bank $L$ is denoted by $R_{l}(l)$, which is proved to be monotone decreasing in $l$ in the proof of Proposition 1. The perfect Bayesian equilibrium strategy in the second competition to be derived is $\left\{G\left(R_{w}\right), q, R_{l}(l)\right\}$.

\footnotetext{
${ }^{7}$ It is assumed that no bank received any additional private signal at Date 2. This assumption is plausible since the private evaluation of the borrower does not seem to change in the absence of any additional experience with the borrower.
} 
The expected return for Bank $W$ when it bids $R_{w}$ is

$$
\frac{F\left(R_{l}^{-1}\left(R_{w}\right) \mid G\right)}{F(w \mid G)}\left(R_{w}-I\right) \nu_{w}(w)-\frac{F\left(R_{l}^{-1}\left(R_{w}\right) \mid B\right)}{F(w \mid B)} I\left(1-\nu_{w}(w)\right)
$$

$\frac{F\left(R_{l}^{-1}\left(R_{w}\right) \mid G\right)}{F(w \mid G)}$ is the probability of Bank $W$ winning when the firm is good, and $\frac{F\left(R_{l}^{-1}\left(R_{w}\right) \mid B\right)}{F(w \mid B)}$ is the probability of winning when the firm is bad. The expected return for Bank $L$ is

$$
\left\{q\left(1-G\left(R_{l}(l)\right)\right)+1-q\right\}\left\{\left(R_{l}(l)-I\right) \nu_{l}(l, w)-I\left(1-\nu_{l}(l, w)\right)\right\}
$$

If the expected return for Bank $W$ when it wins the second competition is smaller than that for Bank $L$, then the expected return for Bank $W$ from the second competition is zero in the equilibrium according to Theorem 2 in Engelbrecht-Wiggans, Milgrom, and Weber [14]. Indeed, it is proved that Bank $L$ evaluates the second loan higher than Bank $W$ in the proof of the next lemma.

Lemma 1 The expected return for Bank $W$ from the second competition is zero in the equilibrium.

The intuitive explanation of this result is as follows. The learning from the previous competition has asymmetric effects on Bank $W$ and Bank $L$. It makes Bank $W$ more pessimistic about the type of the firm, since the fact of winning implies that the rival bank has more pessimistic information about the firm. In contrast, the fact of losing and the observable winner's private signal $w$ make Bank $L$ more optimistic, since it implies that the rival has more optimistic information about the creditworthiness of the firm. If Bank $W$ wins again in the second competition, although it bids more cautiously after learning that the rival bank is more pessimistic from the outcome in the first competition, Bank $W$ realizes that Bank $L$ has very bad information about the firm. This makes Bank $W$ even more pessimistic. Consequently, the expected return for Bank $W$ when it wins again in the second competition is smaller than that for Bank $L$. Bank $L$ can always bid down to the level at which Bank $W$ cannot obtain the expected positive return, while keeping its own expected profit positive since the subjective evaluation by Bank $L$ of the second loan is better than that by Bank $W$ and, moreover, Bank $L$ knows exactly how Bank $W$ 
evaluates the second loan. Lemma 1 is the key that yields the "excessive screening" in the first competition.

Each bank participates in the second competition if and only if its expected return from bidding is non-negative. If Bank $L$ receives a very low signal, then it anticipates a high default probability. Bank $L$ tries to cover the expected default costs by quoting a higher interest rate when the private signal is low. However, if the signal is too low and the default probability is expected to be too high, Bank $L$ cannot fully cover the expected default cost since the interest rate is at best the highest possible revenue for the firm, $V$. In this case, the bank refuses to extend a loan. The screening threshold $s_{* 2}^{t l}$ with respect to Bank $L$ 's private signal is implicitly defined by

$$
\frac{V-I}{I}=\frac{f(w \mid B)}{f(w \mid G)} \frac{1-\mu\left(s_{* 2}^{t l}\right)}{\mu\left(s_{* 2}^{t l}\right)} .
$$

$s_{* 2}^{t l}$ is the point where Bank $L$ 's profit (8) is zero even if it offers the highest interest rate $V$. It is possible to show that there exists a unique $s_{* 2}^{t l}$ if the highest possible profit rate from the project $(V-I) / I$ is within a moderate range. The following lemma summarizes this condition.

Lemma 2 (Existence of a Unique $s_{* 2}^{t l}$ ) Under Assumption (1), a unique $s_{* 2}^{t l}(w) \in(\underline{s}, \bar{s}]$, which is implicitly defined by Equation (9), exists if the exogenous parameters satisfy the inequality:

$$
\frac{1-\gamma}{\gamma}\left(\frac{f(\underline{s} \mid B)}{f(\underline{s} \mid G)}\right)^{2} \frac{f(\bar{s} \mid B)}{f(\bar{s} \mid G)}>\frac{V-I}{I}>\frac{1-\gamma}{\gamma}\left(\frac{f(\bar{s} \mid B)}{f(\bar{s} \mid G)}\right)^{2} .
$$

Assumption (10) holds in the following analyses. Based on Lemmas 1 and 2, the equilibrium strategy of each bank can be derived.

Proposition 1 (Second Competition under Transaction Banking) Under Assumptions (1), (2), and (10), there exists an equilibrium in the second competition under transaction banking where:

1. Bank $W$ participates in the second competition with probability

$$
q=1-\frac{F\left(s_{* 2}^{t w}(w) \mid G\right)}{F(w \mid G)}
$$


Its bid $R_{w}$ follows the cumulative distribution function

$$
G\left(R_{w}\right)=\frac{F(w \mid G)-F\left(R_{l}^{-1}\left(R_{w}\right) \mid G\right)}{F(w \mid G)-F\left(s_{* 2}^{t w}(w) \mid G\right)} .
$$

$s_{* 2}^{t w}(w)$ is implicitly defined by

$$
\frac{V-I}{I}=\frac{F\left(s_{* 2}^{t w} \mid B\right)}{F\left(s_{* 2}^{t w} \mid G\right)} \frac{1-\mu(w)}{\mu(w)} .
$$

2. Bank $L$ bids when its private signal $l$ is greater than $s_{* 2}^{t l}(w)$, which is implicitly defined by Equation (9). If $l \in\left[s_{* 2}^{t w}(w), w\right]$, its bid function is

$$
R_{l}(l, w)=\left(1+\frac{F(l \mid B)}{F(l \mid G)} \frac{1-\mu(w)}{\mu(w)}\right) I .
$$

If $l \in\left[s_{* 2}^{t l}(w), s_{* 2}^{t w}(w)\right]$, Bank $L$ bids $V$.

\section{(2) Case 2: Neither banks extended a loan in the first competition.}

If no bank lent in the first competition, then each bank knows that the private signal of the rival bank is less than the screening threshold $s_{* 1}^{t}$ in the first competition; this will be derived in the next section. This works as a very bad news. In fact, it can be shown that nobody offers a loan to a firm, which is unable to obtain a loan in the first competition.

Lemma 3 If neither bank extended a loan to the firm in the first competition, no bank will offer a loan to the firm in the second competition under Assumptions (1), (2), and (10).

\subsection{First Competition}

The expected return for each bank at the first competition when it receives a private signal $s_{i}$ but pretends to have a signal $x$, and given that the rival adheres to the monotone bidding strategy, where the bid function $R_{1}$ is monotone decreasing in a private signal, is

$$
\begin{aligned}
\pi_{1}\left(x ; s_{i}\right)= & F(x \mid G)\left(R_{1}(x)-I\right) \mu\left(s_{i}\right)-F(x \mid B) I\left(1-\mu\left(s_{i}\right)\right) \\
& +\left(\int_{x}^{\bar{s}}\left(R_{l}\left(s_{i}, w\right)-I\right) \frac{F\left(s_{i} \mid G\right)}{F(w \mid G)} f(w \mid G) d w\right) \mu\left(s_{i}\right) \\
& -I\left(\int_{x}^{\bar{s}} \frac{F\left(s_{i} \mid G\right)}{F(w \mid G)} f(w \mid B) d w\right)\left(1-\mu\left(s_{i}\right)\right) \quad \text { if } \quad x>s_{i},
\end{aligned}
$$




$$
\begin{aligned}
\pi_{1}\left(x ; s_{i}\right)= & F(x \mid G)\left(R_{1}(x)-I\right) \mu\left(s_{i}\right)-F(x \mid B) I\left(1-\mu\left(s_{i}\right)\right) \\
& +\left(\int_{s_{i}}^{\bar{s}} \frac{F\left(s_{i} \mid G\right)}{F(w \mid G)}\left(R_{l}\left(s_{i}, w\right)-I\right) f(w \mid G) d w\right) \mu\left(s_{i}\right) \\
& -I\left(\int_{s_{i}}^{\bar{s}} \frac{F\left(s_{i} \mid G\right)}{F(w \mid G)} f(w \mid B) d w\right)\left(1-\mu\left(s_{i}\right)\right) \\
& +\left(\int_{x}^{s_{i}}\left(R_{l}(w, w)-I\right) f(w \mid G) d w\right) \mu\left(s_{i}\right) \\
& -I\left(F\left(s_{i} \mid B\right)-F(x \mid B)\right)\left(1-\mu\left(s_{i}\right)\right) \quad \text { if } \quad x \leq s_{i} .
\end{aligned}
$$

The first line in each equation is the expected return from the first competition. The next two terms are the expected return from the second competition when Bank $i$ loses the first competition, which is derived in Proposition 1. In the calculation, we need to consider the expected value of the winner's private signal $w$. The last two terms in Equation (16) are the expected return from the second competition when the rival with a private signal between $x$ and $s_{i}$ wins the first competition. In this case, the return to Bank $i$ in the second competition is decreasing in $R_{l}$ under the first order condition in the second competition (Proposition 1). Therefore, it offers the minimum bid, $R_{l}(w, w)$.

Using the revelation principle, we can characterize the symmetric perfect Bayesian equilibrium bidding strategy by the incentive compatibility condition and the individual rationality condition as

$$
\left.\frac{d \pi_{1}}{d x}\right|_{x=s_{i}}=0
$$

(Payoff from participating in the first competition)

$\geq$ (Payoff from not participating in the first competition).

The derivative of Equations (15) and (16) with respect to $x$ is continuous at $x=s_{i}$. The incentive compatibility condition (17) is

$$
R_{1}^{\prime}\left(s_{i}\right)+\frac{f\left(s_{i} \mid G\right)}{F\left(s_{i} \mid G\right)}\left(R_{1}\left(s_{i}\right)-R_{l}\left(s_{i}, s_{i}\right)\right)=0 .
$$

The individual rationality condition (18) can be simplified in the statement in the following lemma. 
Lemma 4 (Individual Rationality Condition) Each bank bids if and only if $s_{i} \geq s_{* 1}^{t}$, where $s_{* 1}^{t}$ is implicitly defined by

$$
\frac{V-I}{I}=\frac{F\left(s_{* 1}^{t} \mid B\right)}{F\left(s_{* 1}^{t} \mid G\right)} \frac{1-\mu\left(s_{* 1}^{t}\right)}{\mu\left(s_{* 1}^{t}\right)} .
$$

A unique $s_{* 1}^{t} \in(\underline{s}, \bar{s}]$ exists under Assumptions (1) and (10).

At $s_{i}=s_{* 1}^{t}$, Bank $i$ is the only participant if Bank $i$ wins. Therefore, Bank $i$ bids the monopolistic rate, i.e.,

$$
R_{1}\left(s_{* 1}^{t}\right)=V
$$

A unique symmetric perfect Bayesian equilibrium bid function can be derived by solving the linear differential equation (19) under the boundary condition (21). The equilibrium is summarized in the following proposition.

Proposition 2 (First Competition for Transaction Banking) Under Assumptions (1), (2), and (10), there exists a unique symmetric perfect Bayesian equilibrium in the first competition. In this equilibrium, Bank $i(=1,2)$ that has a private signal $s_{i} \geq s_{* 1}^{t}$ bids

$$
R_{1}\left(s_{i}\right)=V \frac{F\left(s_{* 1}^{t} \mid G\right)}{F\left(s_{i} \mid G\right)}+\frac{I}{F\left(s_{i} \mid G\right)} \int_{s_{* 1}^{t}}^{s_{i}} \frac{F(t \mid B)}{F(t \mid G)} f(t \mid B) d t
$$

where $s_{* 1}^{t}$ is implicitly defined by Equation (20). The bid function is strictly decreasing in signal $s_{i}$. If a bank draws $s_{i}<s_{* 1}^{t}$, then it does not bid.

The uniqueness of the equilibrium can be verified by applying Theorem 1 in Lizzeri and Persico [24], which proves the uniqueness of the monotone strategy equilibrium in a first-price auction with reservation value. Proposition 1, Lemma 3, and Proposition 2 describe the strategy in the symmetric perfect Bayesian equilibrium.

\subsection{Excessive Screening in Transaction Banking}

The ex ante social welfare depends only on the strength of the creditworthiness test, or the level of the threshold $s_{* 1}^{t}$ in the first competition, which depends on the public information available 
prior to receiving a private signal. The interest $R_{1}-I$ is simply an income transfer within an economy. ${ }^{8}$ Therefore, the ex ante efficiency effect of learning from the past winner's private signal can be predicted by examining the discrepancy between the competitive screening $s_{* 1}^{t}$ and the ex ante second-best screening. If the competitive screening is too strict, or the threshold $s_{* 1}^{t}$ is higher than the second-best level, it can be concluded that potentially profitable projects are passed up to an excessive extent. If the screening is too lax, it can be concluded that potentially unprofitable projects are carried out to an excessive extent.

The return for Bank $W$ from participating in the second competition is zero (Lemma 1) even if the expected social benefit from the second loan is positive. Consequently, each bank underestimates the value of winning the first competition relative to the positive social impact through enhancing the willingness of the rival to offer a loan that has a positive expected social value in the second competition. This "informational externality" results in the excessive screening in the first competition under transaction banking in an economy with a sophisticated credit reporting system.

Proposition 3 (Excessive Screening) Under Assumptions (1), (2), and (10), the competitive screening threshold in the first competition for transaction banking is stricter than that in the ex ante second-best level.

\subsection{Alternative Assumptions about the Public Observability of a Winner's Private Signal}

In the previous sections, we analyzed the problem under the assumption that the winner's private signal is publicly observable while the loser's one is not. This assumption arises from the observation that banks can directly or indirectly obtain information about credit terms, such as amounts, maturity, or interest rates, which reflect the past lender's private information from a borrower's credit history and financial statements available from public or private credit reporting systems in most developed countries, while it is almost impossible to know the private information held by a bank that has never extended a loan to the firm. The following sections

\footnotetext{
${ }^{8}$ It is well known that the level of interest rates affects entrepreneurs' incentives to make an effort (Rajan [29]), thus social welfare. We focus here on the welfare effects through the willingness by banks to lend.
} 
demonstrate, by examining differences in the outcome under alternative assumptions, that the observability of the winner's private signal is crucial for the existence of the excessive screening problem while the unobservability of a loser's private signal is not. It is also shown that hiding the winner's private information is worse for an economy despite the resulting absence of the excessive screening problem. This last point is consistent with the theoretical and empirical findings of Jappelli and Pagano ([21, 22]).

\section{(1) When private signals of both banks are observable after the first bid.}

Excessive screening can be obtained under the assumption of a perfect credit register, such that it can publicly inform the private signals of both banks after the first bid. In this case, the posterior belief of each bank about the probability that the borrower is a good firm after the first bid is identical and equal to

$$
\nu=\frac{\gamma f(l \mid G) f(w \mid G)}{\gamma f(l \mid G) f(w \mid G)+(1-\gamma) f(l \mid B) f(w \mid B)} .
$$

The expected return for each bank from bidding the second offer $R_{2}$ is

$$
\nu\left(R_{2}-I\right)-(1-\nu) I
$$

The second competition is a simple Bertrand competition since each bank has symmetric information and a symmetric payoff function. Therefore, the expected return of each bank is equal to zero. Each bank bids

$$
R_{2}=\left(1+\frac{(1-\gamma) f(l \mid B) f(w \mid B)}{\gamma f(l \mid G) f(w \mid G)}\right) I
$$

Bank $W$ always wins under the tie-breaking assumption. Each bank bids in the second competition as long as the private signal $l$ is greater than $s_{* 2}^{t}$ for a given $w$, which is implicitly defined by

$$
\frac{V-I}{I}=\frac{(1-\gamma) f\left(s_{* 2}^{t} \mid B\right) f(w \mid B)}{\gamma f\left(s_{* 2}^{t} \mid G\right) f(w \mid G)}
$$

In the first competition, the competitive screening threshold $s_{* 1}^{t}$ is implicitly defined by Equation (20) in the same way as it is in the case where only the winning bid is observable. The 
ex ante social welfare from two loans to a firm is equal to

$$
\begin{aligned}
\left(1-F^{2}\left(s_{* 1}^{t} \mid G\right)\right)(V-I) \gamma-\left(1-F^{2}\left(s_{* 1}^{t} \mid B\right)\right) I(1-\gamma) \\
\quad+\int_{s_{* 1}^{t}}^{\bar{s}}\left(1-F\left(s_{* 2}^{t}(w) \mid G\right)\right) 2 f(w \mid G) F(w \mid G) d w(V-I) \gamma \\
\quad-\int_{s_{* 1}^{t}}^{\bar{s}}\left(1-F\left(s_{* 2}^{t}(w) \mid B\right)\right) 2 f(w \mid B) F(w \mid B) d w I(1-\gamma) .
\end{aligned}
$$

The first line is the ex ante social return from the first loan. The second and third lines are the ex ante social return from the second loan. Rearranging the first order condition with respect to $s_{* 1}^{t}$ to maximize the social return gives the same conclusion as in Proposition 3. Thus, the unobservability of a losing bid is not crucial for the existence of the excessive screening problem.

\section{(2) When private signals of both the banks are not observable after the first bid}

The excessive screening problem disappears if neither of the banks can obtain the information about the rival private signal, although they can detect whether any bank has extended a loan in the first competition. In the second bid, Bank $W$ knows from the fact that it wins that its rival has a private signal that is lower than its own signal. Therefore, it believes that the borrower is a good firm with a probability of

$$
\nu_{w}(w)=\frac{\mu(w) F(w \mid G)}{\mu(w) F(w \mid G)+(1-\mu(w)) F(w \mid B)} .
$$

Bank $L$ knows that its rival has a private signal that is higher than its own. Therefore, it believes that the borrower is a good firm with a probability of

$$
\nu_{l}(l)=\frac{\mu(l)(1-F(l \mid G))}{\mu(l)(1-F(l \mid G))+(1-\mu(l))(1-F(l \mid B))} .
$$

The key difference from the previous section is that the posterior belief of Bank $L$ does not depend on the implied winner's signal $w$. The expected return for Bank $W$ when it bids $R_{w}$ in the second competition is

$$
\frac{F\left(R_{l}^{-1}\left(R_{w}\right) \mid G\right)}{F(w \mid G)}\left(R_{w}-I\right) \nu_{w}(w)-\frac{F\left(R_{l}^{-1}\left(R_{w}\right) \mid B\right)}{F(w \mid B)} I\left(1-\nu_{w}(w)\right)
$$

The expected return for Bank $L$ when it bids $R_{l}$ is

$$
\frac{F\left(R_{w}^{-1}\left(R_{l}\right) \mid G\right)}{1-F(l \mid G)}\left(R_{l}-I\right) \nu_{l}(l)-\frac{F\left(R_{w}^{-1}\left(R_{l}\right) \mid B\right)}{1-F(l \mid B)} I\left(1-\nu_{l}(l)\right) .
$$


The first order conditions to maximize these returns with respect to $R_{w}$ and $R_{l}$, respectively, are identical. The screening threshold in the second competition $s_{* 2}^{t}$ is also identical for each bank, and this is determined at the point where the payoff to each bank is equal to zero when they offer the highest possible bid $V$, i.e.,

$$
\frac{V-I}{I}=\frac{F\left(s_{* 2}^{t} \mid B\right)}{F\left(s_{* 2}^{t} \mid G\right)} \frac{1-\mu\left(s_{* 2}^{t}\right)}{\mu\left(s_{* 2}^{t}\right)} .
$$

Therefore, the bid functions of Bank $W$ and Bank $L$ are identical in the second bid. In the first competition, the expected return for Bank $i$ with a private signal $s_{i}$ is equal to

$$
\begin{aligned}
F\left(s_{i} \mid G\right) & \left(R_{1}\left(s_{i}\right)-I\right) \mu\left(s_{i}\right)-F\left(s_{i} \mid B\right) I\left(1-\mu\left(s_{i}\right)\right) \\
& +F\left(s_{i} \mid G\right)\left(R_{w}\left(s_{i}\right)-I\right) \mu\left(s_{i}\right)-F\left(s_{i} \mid B\right) I\left(1-\mu\left(s_{i}\right)\right) \\
& +F\left(s_{i} \mid G\right)\left(R_{l}\left(s_{i}\right)-I\right) \mu\left(s_{i}\right)-F\left(s_{i} \mid B\right) I\left(1-\mu\left(s_{i}\right)\right) .
\end{aligned}
$$

The screening threshold regarding a private signal in the first competition $s_{* 1}^{t}$ is determined at the point where this expression is equal to zero at $R_{1}=V$, but it turns out that it is the same as the one in the second competition as defined by Equation (32). The ex ante social return from the two loans is equal to

$$
2\left\{\left(1-F^{2}\left(s_{* 1}^{t} \mid G\right)\right)(V-I) \gamma-\left(1-F^{2}\left(s_{* 1}^{t} \mid B\right)\right) I(1-\gamma)\right\}
$$

The first order condition with respect to $s_{* 1}$ to maximize this value is identical to Equation (32). Therefore, the excessive screening problem does not occur in this case.

The key difference from the original set-up that yields this result is the fact that the screening threshold in the second competition, which is defined by Equation (32), is independent of the winner's private signal $w$. Thus, the source of the informational externality and the resulting excessive screening are the ex post public observability of the winner's private signal after the first competition.

Despite the disappearance of excessive screening in the unobservable winner's signal case, the welfare in this case is lower than the observable winner's signal case. This point can be readily verified by calculating the difference between the welfare in the unobservable case (34) and that 
in the observable case (66), considering the definition of the screening threshold of Bank $L$ in the second competition $s_{* 2}^{t l}$ (Equation (9)). Furthermore, it turns out that the credit availability in the second competition is lower than the observable winner's signal case by comparing Equation (9) and Equation (32) under Assumption (1). Thus, simply hiding the winner's private signal is worse than the welfare loss due to the excessive screening. The next proposition summarizes these results.

Proposition 4 (Benefit of Information Sharing) Under Assumptions (1), (2), and (10), the ex ante welfare and the credit availability in the second competition are greater when the private signal of the incumbent lender is observable after the first competition than it is otherwise.

In other words, ex post information sharing by credit reporting systems improves welfare by enhancing credit availability to existing firms, as shown by Jappelli and Pagano [21]. However, there is still room to improve the economic efficiency with regard to credit availability for new firms. The next section shows that relationship banking is a possible endogenous strategy to achieve it.

\section{Relationship Banking as a Remedy for Excessive Screening Problem}

The key element leading to the excessive screening problem in transaction banking is the possibility that the private signal of Bank $W$ is revealed to Bank $L$ through the terms of a past loan that are publicly observable in a credit reporting system. This information revelation results in the situation in which Bank $W$ earns, at most, zero profit from the second competition although the expected social benefit from the second loan is positive. The straightforward remedy for Bank $W$ to protect against such disadvantage is to collect more precise information that the outside rival cannot acquire by taking advantage of its status as an incumbent creditor. This point highlights an incentive for banks to undertake relationship banking for competitive reasons. Bank $W$ attempts to informationally differentiate itself from its rival as long as the return from the differentiation is large enough to cover the additional information acquisition cost. In 
such a case, each bank will be more willing to extend a loan in the first competition so as to ensure a profit in the future by pre-empting a customer relationship. Thus, endogenous relationship banking alleviates costly excessive screening in transaction banking. We will analyze relationship banking primarily as a typical business strategy although it is not the only strategy for Bank $W$ to prevent the loss arising from the informational disadvantage. Alternative strategies for Bank $W$ will be discussed in Section 4.5.

In this section, it is assumed that Bank $W$ can choose whether to monitor a borrower after extending the first loan by paying a fixed cost $c$ to acquire perfect information about the type of borrower. It is assumed that the information acquired through the monitoring is accessible exclusively to Bank $W$. This is true especially for "innovative" firms, since these would be unwilling to reveal information about new business strategies or new technologies to rivals. These firms reveal such strategically important information only to a limited range of important financiers such as a "primary" bank (Campbell [8]). In order to ensure the reliability of the information, the bank needs to commit human resources to monitor the firm. The cost $c$ represents such personnel expenses.

It is assumed that the choice between relationship banking and transaction banking is publicly observable at Date 2. Under this assumption, the problem becomes tractable by avoiding the case in which a bank "disguises" relationship banking. The competition for relationship banking is modeled as a twice-repeated auction under asymmetric information, which is an extension of the multi-unit demand sequential common-value first-price auction presented by Engelbrecht-Wiggans and Weber [13], in the case in which an uninformed bidder has private information that is less accurate than that of the informed bidder. An alternative way to approach this problem is to formulate it as a one-time interbank competition for a long-term, renegotiation-proof contract including information provision by the borrower. However, this paper takes the repeated auction approach so as to focus on competitive allocation amongst possible efficient allocations that renegotiation-proofness requires in the renegotiation stage. A perfect Bayesian equilibrium of the sequential auction is derived backward. 


\subsection{Second Competition}

The outcome in the second competition when the winning bank opts for transaction banking has already been shown in the previous section. This section focuses on the case in which Bank $W$ opts for relationship banking after winning in the first competition. The winner's private signal $w$ is assumed to be publicly observable through the terms of a past loan that are published by a credit reporting system, as in the case of transaction banking. Bank $L$ updates its belief by the winner's private signal $w$. Bank $L$ believes that the firm is good with a probability of $\nu_{l}(l, w)$ (Equation $\left.(6)\right)$. Based on this belief, it bids $R_{l}(l, w)$ in the second competition. Bank $W$, having collected the perfect information about the type of firm involved, bids $R_{w}$, which is distributed according to a cumulative distribution function $H\left(R_{w}\right)$, if the firm is turned out to be good following the interim monitoring between Date 1 and Date 2. Otherwise, it does not bid. The expected return for Bank $W$ at Date 2 is

$$
\pi_{w}= \begin{cases}\frac{F\left(R_{l}^{-1}\left(R_{w}\right) \mid G\right)}{F(x \mid G)}\left(R_{w}-I\right) & \text { if type }=G, \\ 0 & \text { if type }=B .\end{cases}
$$

The expected return for Bank $L$ at Date 2 is

$$
\pi_{l}=\left\{1-H\left(R_{l}(l, w)\right)\right\}\left(R_{l}(l, w)-I\right) \nu_{l}(l, w)-I\left(1-\nu_{l}(l, w)\right) .
$$

The equilibrium in the second competition, based on these payoff functions, is summarized in the following proposition.

Proposition 5 (Second Competition under Relationship Banking) Under Assumptions (1), (2), and (10), there exists an equilibrium in the second competition under relationship banking if there exists a perfect Bayesian equilibrium in the first competition, where the bid function of each bank is monotone decreasing in its private signal, and if a bank wins by bidding $R_{1}(x)$ in the first competition. In the equilibrium,

1. if type $=G$, Bank $W$ bids $R_{w}$ that is distributed according to the cumulative distribution function

$$
H\left(R_{w}\right)=\frac{F(w \mid G)-F\left(R_{l}^{-1}\left(R_{w}\right) \mid G\right)}{F(w \mid G)}
$$


and it bids $V$ with a probability of $\frac{F\left(s_{* 2}^{r l} \mid G\right)}{F(w \mid G)}$. If type $=B$, Bank $W$ does not bid. The expected return for Bank $W$ is

$$
\frac{F\left(s_{* 2}^{r l}(w) \mid G\right)}{F(x \mid G)}(V-I) .
$$

2. If $l \in\left[s_{* 2}^{r l}(w), w\right)$, Bank $L$ bids

$$
R_{l}(l, w)=\frac{F\left(s_{* 2}^{r l}(w) \mid G\right)}{F(l \mid G)}(V-I)+I,
$$

where $s_{* 2}^{r l}(w)$ is implicitly defined by

$$
\frac{V-I}{I}=\frac{1-\nu_{l}\left(s_{* 2}^{r l}, w\right)}{\nu_{l}\left(s_{* 2}^{r l}, w\right)} \frac{F(w \mid G)}{F\left(s_{* 2}^{r l} \mid G\right)}
$$

If $l \geq w$, Bank L bids

$$
R_{l}(w, w)=\frac{F\left(s_{* 2}^{r l}(w) \mid G\right)}{F(w \mid G)}(V-I)+I
$$

Otherwise, it does not bid. The expected return to Bank $L$ is

$$
\frac{F\left(s_{* 2}^{r l}(w) \mid G\right)}{F(w \mid G)}(V-I) \nu_{l}(l, w)-I\left(1-\nu_{l}(l, w)\right)
$$

The expected return to Bank $W$ is positive owing to the additional private information that is not accessible to the outside rival. This profit yields the incentive to undertake relationship banking and, consequently, enhances the willingness of banks to lend in the first competition.

\subsection{Choice between Relationship Banking and Transaction Banking in the Symmetric Equilibrium}

Bank $W$ can decide to collect additional proprietary information at a cost of $c$ after winning by bidding $R_{1}(w)$ in the first competition. If each bank plays the monotone bidding strategy in the first competition, the expected return for Bank $W$ from the second competition under relationship banking will be

$$
\nu_{w}(w) \frac{F\left(s_{* 2}^{r l}(w) \mid G\right)}{F(w \mid G)}(V-I)-c
$$


where $\nu_{w}$ is defined by Equation (5). Bank $W$ chooses relationship banking provided that the expected return exceeds the expected return from transaction banking, which is equal to 0 . The decision depends on $w$. Simple algebra shows that the expected return, Equation (43), is monotone decreasing in $w$ under the assumption

$$
\frac{d}{d w} \frac{f(w \mid B)}{f(w \mid G)}>\max \left[-\frac{f(w \mid B)}{F(w \mid B)}, \frac{1-\nu(w, w)}{\nu(w, w)} \frac{f(w \mid B)}{f(w \mid G)}\left(\frac{f(w \mid B)}{F(w \mid B)}-\frac{f(w \mid G)}{F(w \mid G)}\right)\right] .
$$

The assumption requires that the free signal that each bank obtains at the beginning of the first competition is not too informative. The lower the winning bid in the first competition, the more aggressive the rival bank will be, and the smaller the expected return to Bank $W$ in the second competition. Therefore, it is unlikely that Bank $W$ chooses relationship banking when it wins in the first competition with a lower bid. It is assumed that the inequality (44) holds in the following analysis. The threshold $s_{r}$ regarding an initial private signal, above which Bank $W$ chooses transaction banking and below which Bank $W$ chooses relationship banking, is uniquely determined by the equation

$$
\nu_{w}\left(s_{r}\right) \frac{F\left(s_{* 2}^{r l}\left(s_{r}\right) \mid G\right)}{F\left(s_{r} \mid G\right)}(V-I)=c
$$

\subsection{First Competition}

If a bank obtains a private signal $s_{i}$ that is less than or equal to $s_{r}$, it expects to undertake relationship banking when it wins in the first competition, since the winner's private signal $w$ is observable to the rival after the first competition. In this case, the three ways for Bank $i$ with a private signal $s_{i}$ to deviate alone from the monotone bidding strategy by bidding $R_{1}(x)$, where $x$ is not necessarily equal to the true private signal $s_{i}$, are as follows:

1. $s_{r} \geq x>s_{i}$,

2. $x \geq s_{r} \geq s_{i}$,

3. $s_{r} \geq s_{i} \geq x$. 
In Cases 1 and 3, the rival bank opts for transaction banking if it wins the first competition and its signal is greater than or equal to $s_{r}$, but it opts for relationship banking otherwise. In Case 2 , the rival bank opts for transaction banking if it wins the first competition.

If a bank obtains a private signal $s_{i}$ that is greater than $s_{r}$, it expects to undertake transaction banking when it wins in the first competition. As in the previous case, the three ways for Bank $i$ with a private signal $s_{i}$ to deviate alone from the monotone bidding strategy by bidding $R_{1}(x)$, where $x$ is not necessarily equal to the true private signal $s_{i}$, are as follows:

1. $s_{i} \geq x>s_{r}$,

2. $s_{i}>s_{r}>x$,

3. $x \geq s_{i}>s_{r}$.

In Cases 1 and 3, the rival bank opts for transaction banking if it wins the first competition. In Case 2, the rival bank opts for transaction banking if it wins the first competition and its signal is greater than or equal to $s_{r}$ but it opts for relationship banking otherwise.

Using the revelation principle, the symmetric equilibrium bid in the first competition can be derived from the participation constraint, which requires that the payoff from participating in the first competition is greater than or equal to the payoff from not participating in the first competition, and the incentive compatibility condition $\left.\frac{d \pi_{1}}{d x}\right|_{x=s_{i}}=0$. The existence of a unique symmetric perfect Bayesian equilibrium in the first competition, where Bank $i$ bids $R_{1}\left(s_{i}\right)$ ( $s_{i}$ is the true private signal of Bank $i$ ), can be verified by examining the sign of the derivative of the expected return with respect to $x$ under the incentive compatibility condition of the rival playing the equilibrium monotone strategy in each case when Bank $i$ expects to undertake transaction banking and when it expects to undertake relationship banking, as is shown in the proof of Proposition 6. The equilibrium strategy in the second competition is that given by Proposition 5 at $x=w$. The unique perfect Bayesian equilibrium in the first competition is summarized in the following proposition. 
Proposition 6 (First Competition for Possible Relationship Banking) Under Assumptions (1), (2), (10), and (44), there exists a unique symmetric perfect Bayesian equilibrium in the first competition for potential relationship banking. In the equilibrium, Bank $i(=1,2)$ bids

$$
R_{1}\left(s_{i}\right)= \begin{cases}R_{1}^{r}\left(s_{i}\right) & \text { if } s_{r} \geq s_{i} \geq s_{* 1}^{r} \\ R_{1}^{t}\left(s_{i}\right) & \text { if } s_{i} \geq s_{r}\end{cases}
$$

where

$$
\begin{aligned}
& R_{1}^{r}\left(s_{i}\right)=I+\left\{\frac{F\left(s_{* 1}^{r} \mid G\right)}{F\left(s_{i} \mid G\right)}+\int_{s_{* 1}^{r}}^{s_{i}} \frac{f(t \mid G)}{F(t \mid G)} \frac{F\left(s_{* 2}^{r l}(t) \mid G\right)}{F\left(s_{i} \mid G\right)} d t\right\}(V-I) \\
&+c\left\{1-\frac{F\left(s_{* 1}^{r} \mid G\right)}{F\left(s_{i} \mid G\right)}+\int_{s_{* 1}^{r}}^{s_{i}} \frac{f(t \mid G)}{F\left(s_{i} \mid G\right)} \frac{1-\nu_{l}(t, t)}{\nu_{l}(t, t)} d t\right\}, \\
& R_{1}\left(s_{i}\right)=R_{1}^{r}\left(s_{r}\right) \frac{F\left(s_{r} \mid G\right)}{F\left(s_{i} \mid G\right)}+\frac{I}{F\left(s_{i} \mid G\right)} \int_{s_{r}}^{s_{i}} \frac{F(t \mid B)}{F(t \mid G)} f(t \mid B) d t,
\end{aligned}
$$

where $s_{r}$ is defined by Equation (45). $R_{1}\left(s_{i}\right)$ is monotone decreasing in $s_{i}$. Bank $i$ does not bid if $s_{i}<s_{* 1}^{r}$. The screening threshold in relationship banking $s_{* 1}^{r}$ is implicitly defined by

$$
\begin{aligned}
\frac{V-I}{I}=\frac{F\left(s_{* 1}^{r} \mid B\right)}{F\left(s_{* 1}^{r} \mid G\right)} \frac{1-\mu\left(s_{* 1}^{r}\right)}{\mu\left(s_{* 1}^{r}\right)} & \\
& -\frac{1}{I \nu_{w}\left(s_{* 1}^{r}\right)}\left(\nu_{w}\left(s_{* 1}^{r}\right) \frac{F\left(s_{* 2}^{r l}\left(s_{*}^{r}\right) \mid G\right)}{F\left(s_{* 1}^{r} \mid G\right)}(V-I)-c\right) .
\end{aligned}
$$

If $s_{* 1}^{r} \geq s_{* 1}^{t}$, then the equilibrium is the same as described in Proposition 2.

The solid line in Figure 2 depicts the equilibrium bidding strategy in the first competition $R_{1}\left(s_{i}\right)$. The bid function is continuous and monotone decreasing in $s_{i}$. However, it has a kink at the switching point $s_{r}$. The broken curve is the bid function in the case where relationship banking disappears. The screening threshold $s_{* 1}^{r}$ under relationship banking is lower than that under transaction banking $s_{* 1}^{t}$, i.e., the preliminary screening is lax when relationship banking is present than when it is absent. The contents of the parentheses of the second term on the right hand side of Equation (49), which implicitly define $s_{* 1}^{r}$, are the expected return from the second competition under relationship banking. Provided that this expected return is positive, relationship banking emerges and makes each bank more willing to extend a loan in the first competition. Each bank is more willing to extend a loan to a new customer so as to pre-empt 


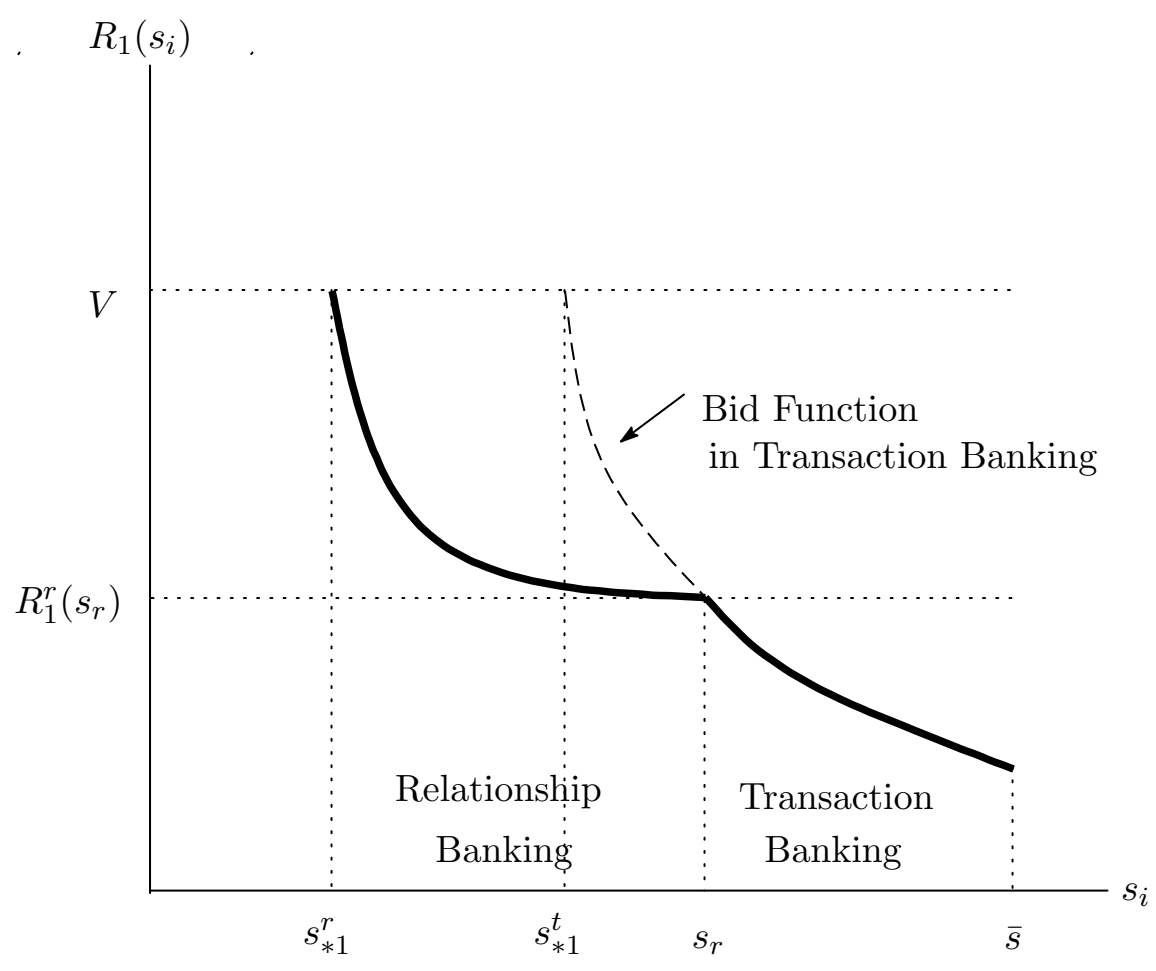

Figure 2: Bid function $R_{1}\left(s_{i}\right)$

the opportunity to establish a customer relationship to the extent that it will be profitable in future lending.

The borrower may prefer transaction banking since relationship banking may lead to higher interest costs in the future; however, it is impossible to choose transaction banking if the winning bank is willing to undertake relationship banking since the other bank with a lower private signal is also willing to undertake relationship banking in case it wins.

\subsection{Ex Ante Welfare in Relationship Banking}

A welfare analysis shows that relationship banking alleviates inefficient excessive screening in transaction banking although it does not necessarily achieve the second-best outcome. The first term on the right hand side of Equation (49) is equal to the right hand side of Equation (20), which determines the competitive screening threshold in transaction banking. The contents 
of the parenthesis of the last term of Equation (49) are the expected return from the second competition under relationship banking, which is positive as long as $s_{* 1}^{r}<s_{r}$. This means that the creditworthiness test in the first competition for possible relationship banking is more lax than that for transaction banking to the extent that Bank $W$ expects a positive return in the future from relationship banking. In fact, it is possible to show that relationship banking is welfare-improving as long as the winner's private signal $w$ does not render Bank $L$ extremely optimistic in the second competition.

\section{Proposition 7 (Screening in the First Bid under Relationship Banking) 1. The com-} petitive screening threshold in relationship banking $s_{* 1}^{r}$ is lower than that in transaction banking $s_{* 1}^{t}$, i.e., relationship banking alleviates excessive screening in transaction banking. The screening threshold $s_{* 1}^{r}$ achieves the second-best allocation if the exogenous parameters $\gamma, V$, and $I$ are set so that the losing bank's screening threshold in the second competition is identical to that in the first competition.

2. The welfare under possible relationship banking is greater than that under transaction banking as long as $s_{* 2}^{r l}(w)$ (defined by Equation (40)) is sufficiently close to $s_{* 1}^{r}$ (defined by Equation (49)).

Figure 3 illustrates social welfare under relationship banking (curve $W_{r}$, Expression (77) in the proof of Proposition 7), transaction banking (curve $W_{t}$, Expression (66) in the proof of Proposition 3), and in the case of unobservable winning bids (curve $W_{u}$, Expression (34) in Section $3.4(2))$. The competitive threshold under transaction banking, and in the case of unobservable winning bids, is equal to $s_{* 1}^{t}$. The welfare in the former case is greater although the second best (the maximal point in curve $W_{t}$ ) is not achieved even in the former case because of the informational externality, as shown in the previous section. The proof of Proposition 7 shows that the welfare under relationship banking is greater than that under transaction banking at $s_{* 1}^{t}$. Therefore, relationship banking improves social welfare as long as the competitive threshold 


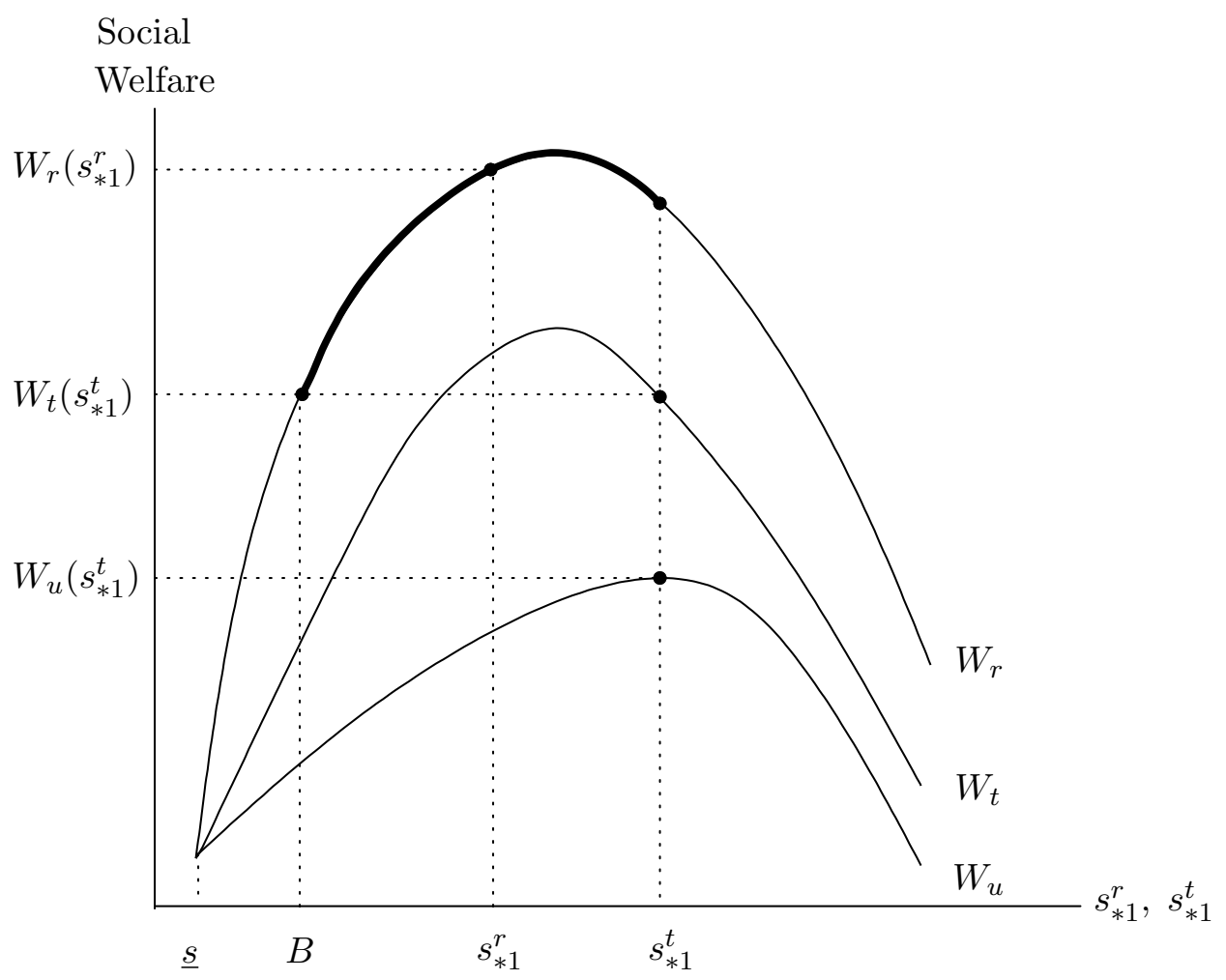

Figure 3: Comparison of Social Welfare

under relationship banking $s_{* 1}^{r}$ is between $B$ and $s_{* 1}^{t}$, as shown in Figure 3 . In other words, relationship banking is welfare-improving if the effect of the over-lending by Bank $L$ in the second competition, resulting from learning from the implied winner's private signal $w$, is small enough.

The competitive screening under relationship banking $s_{* 1}^{r}$ does not generically achieve the second-best allocation. The optimal screening threshold $s_{o}$ for possible relationship banking in the first competition, which is derived by rearranging the first order condition to maximize the ex ante social welfare of two loans, Expression (77), with respect to the screening threshold in the first competition, is implicitly defined by

$$
\begin{aligned}
& \frac{V-I}{I}=\frac{F\left(s_{o} \mid B\right)}{F\left(s_{o} \mid G\right)} \frac{1-\mu\left(s_{o}\right)}{\mu\left(s_{o}\right)}-\frac{1}{I \nu_{w}\left(s_{o}\right)} \\
& \quad \times\left\{\nu_{w}\left(s_{o}\right)(V-I)-c-\left(1-\frac{F\left(s_{* 2}^{r l}\left(s_{o}\right) \mid B\right)}{F\left(s_{o} \mid B\right)}\right)\left(1-\nu_{w}\left(s_{o}\right)\right) I\right\} .
\end{aligned}
$$


The contents of the parentheses in the second line are identical to those in Equation (49) if $s_{o}=s_{* 2}^{r l}\left(s_{o}\right)$ and $s_{* 1}^{r}=s_{* 2}^{r l}\left(s_{* 1}^{r}\right)$. The first term in the parentheses in the second line in Equation (49) is smaller than that in Equation (50). This is because Bank $W$ cannot capture all the social return from relationship banking because of the competition with Bank $L$. This partially limits the effectiveness of relationship banking in alleviating excessive screening. The final term in Equation (50) arises from the possibility that the winning bid by Bank $W$ renders the uninformed Bank $L$ more aggressive and increases the probability of erroneously extending a loan to a bad firm in the second competition. The competitive screening threshold (49) can be excessively lax because of this loss. In the existing literature, it has been shown that a bank causes the over-lending problem in the first competiton because of the possibility that each bank expects too large a return from a lending relationship (Sharpe [33], Dewatripont and Maskin [11]). Instead, the possible over-lending problem in this model arises from the learning by an outside bank, Bank $L$, from the winning bid, reflecting the most optimistic opinion in the market.

Apart from the credit availability problem, interim monitoring is itself ex ante socially desirable if the monitoring cost $c$ is smaller than $(1-\gamma) I$, where $(1-\gamma) I$ is the social return from relationship banking by avoiding non-performing loans. This means that relationship banking may improve the stability of credit markets by avoiding "erroneous" loans. If the firm is in a class that rarely fails, i.e., $(1-\gamma) I$ is close to zero, then relationship banking for this class of firms is socially inefficient. Transaction banking or direct financing from markets is socially desirable for them. However, for informationally opaque firms that have not yet established any good reputation in general, relationship banking is inevitable, since it provides them reasonable access to funds while economizing the social costs of generating non-performing loans.

\subsection{Discussions}

\section{(1) Another strategy for an incumbent lender}

An alternative strategy for an incumbent lender to avoid the informational disadvantage in transaction banking due to the information revelation through a winning bid in the first 
competition is to sell a loan package that includes the incumbent lender's right to match a rival bid in case the rival wins the second competition.

In the corresponding stage after Bank $L$ wins the second competition, Bank $W$ infers that the expected return from the second loan at the interest rate that is offered by Bank $L$ is nonnegative under the posterior belief of Bank $L$, which considers not only the private signal of Bank $W$ but also that of Bank $L$. Therefore, Bank $W$ can win the loan contract with a nonnegative expected value by bidding the same rate as Bank $L$ under the tie-breaking assumption that Bank $W$ wins if two bids tie. Therefore, the expected return for Bank $L$ from bidding in the second competition is equal to zero. Bank $W$ bids the monopolistic rate $V$ in the second competition since it can expect a non-negative return in the matching stage even in the case where it loses, and it can get a monopolistic return in the case where it wins at this rate. Bank $W$ is more willing to extend a loan in the first competition since it can expect a positive return from the second loan. Thus, selling a loan package with the matching right can alleviate the excessive screening problem in the first competition.

This type of loan contract is rarely sold in reality. One of the potential problems of such a contract is the enforceability on the side of the borrowers. Credit registers usually report loan contracts that have already been concluded, not those under negotiation. An incumbent lender cannot obtain credible information about an interest rate offered by Bank $L$ in the second competition. Therefore, it cannot match Bank L's bid effectively. The enforceability problem does not arise in relationship banking as long as an incumbent lender can obtain detailed information about the quality of borrowers without their help.

\section{(2) Entrepreneurs' incentives for sequential financing and the similarity between staged financing by venture capitalists and relationship banking}

Banks are willing to bid and extend a loan in the first competition even if the profit from the first investment by a good firm is 0 , i.e., $V=I$ in the first period, as long as the bank can expect a certain positive return from the relationship in the future. In fact, even if $V=I$ in the left hand side of Equation (49), we can find some $s_{i} \geq s_{* 1}^{r}$ if the expected return from relationship 
banking (the contents of the large parentheses) is sufficiently large. Therefore, some banks are still willing to extend a loan even in this case. In contrast, if $V=I$ for the first period in transaction banking (Equation (20)), there are no $s_{i} \geq s_{* 1}^{t}$, i.e., no banks are willing to extend a loan. Relationship banking enables entrepreneurs to finance businesses that are profitable in the long run but are not profitable in the short run since banks try to pre-empt access to proprietary information that eventually pays off even if the return is negative in the short run. A new firm that has a difficulty in receiving a loan can improve its access to funds by sequential financing instead of one-shot financing to provide an incumbent lender a chance to establish an informational advantage.

In this context, relationship banking is conceptually equivalent to "staged financing" by venture capitalists (e.g., Gompers [17]). A venture capitalist finances some of the initial investment costs for a new firm, and then decides on continuing after inquiring for more precise information. If it chooses to continue, the venture capitalist can earn a bigger return from the informational advantage than rival institutions in the form of a capital gain. This also demonstrates why a bank that intends to undertake relationship banking tries to help temporarily distressed companies. Dinç [12] shows that the incentive to build a reputation as a "lender of last resort" for temporarily distressed companies urge banks to help such companies. The present study shows that the return from informational advantage in the future also generates a similar incentive.

\section{(3) Multiple relationships.}

A firm may try to avoid higher interest costs in relationship banking by establishing lending relationships with multiple banks. However, credit availability decreases since banks cannot expect a positive return from the relationship with the firm. Therefore, a firm whose expected benefits from improved fund accessibility exceed the expected interest costs because of informational lock-in will choose to establish a relationship with a single bank. In this regard, Farinha and Santos [15] tried to empirically extract the incentive for companies to switch to multiple relationships to avoid the informational lock-in costs although they could not reach a clear conclusion. 


\section{Conclusion}

This paper presents a model to analyze the welfare impact of intertemporal information flow among competing banks through past loan terms that are publicly observable by a creditreporting system. The analysis of a dynamic game shows that such information revelation after winning a loan contract causes the excessive screening problem in transaction banking. However, this informational disadvantage generates an incentive for the winning bank to collect additional proprietary information about the borrower that is inaccessible to an outside rival, resulting in endogenous relationship banking. The expected positive return from a customer relationship alleviates the excessive screening problem vis-a-vis a new borrower. Despite the repeated game structure, the present study has not yet seriously looked at the possible collusion among competing banks in terms of loan pricing and information acquisition. It would be an interesting and challenging extension of the above analysis to explicitly treat a collusive arrangement among banks by applying the theory of tacit collusion in repeated auctions (e.g., Aoyagi [1], Skrzypacz and Hopenhayn [34]). The theoretical and empirical analysis of this problem remains a future research subject.

\section{References}

[1] Aoyagi, M. "Bid Rotation and Collusion in Repeated Auctions". Journal of Economic Theory, 112(1):79-105, 2003.

[2] Berger, A., and Udell, G. "Relationship Lending and Lines of Credit in Small Business Finance". Journal of Business, 68(3):351-381, 1995.

[3] Bolton, P., and Sharfstein, D. "A Theory of Predation Based on Agency Problems in Financial Contracting". American Economic Review, 80(1):93-106, 1990.

[4] Boot, A. "Relationship Banking: What Do We Know?". Journal of Financial Intermediation, $9(1): 7-25,2000$.

[5] Boot, A. and Thakor, A. "Moral Hazard and Secured Lending in an Infinitely Repeated Credit Market Game". International Economic Review, 35(4):899-920, 1994.

[6] Boot, A., and Thakor, A. "Can Relationship Banking Survive Competition?". Journal of Finance, 55(2):679-713, 2000.

[7] Broecker, T. "Credit-Worthiness Tests and Interbank Competition". Econometrica, 58(2):429-452, 1990.

[8] Campbell, T. "Optimal Investment Financing Decisions and the Value of Confidentiality". Journal of Financial and Quantitative Analysis, 14(5):913-924, 1979. 
[9] Degryse, H., and Cayseele, P. "Relationship Lending within A Bank-Based System: Evidence from European Small Business Data". Journal of Financial Intermediation, 9(1):90-109, 2000.

[10] Dell'Ariccia, G., Friedman, E., and Marquez, R. "Adverse Selection as a Barrier to Entry in the Banking Industry". Rand Journal of Economics, 30(3):515-534, 1999.

[11] Dewatripont, M. and Maskin, E. "Credit and Efficiency in Centralized and Decentralized Economies". Review of Economic Studies, 62(4):541-555, 1995.

[12] Dinç, I. "Bank Reputation, Bank Commitment, and the Effects of Competition in Credit Markets". Review of Financial Studies, 13(3):781-812, 2000.

[13] Engelbrecht-Wiggans, R., and Weber, R. "A Sequential Auction Involving Asymmetrically-Informed Bidders". International Journal of Game Theory, 12(2):123-127, 1982.

[14] Engelbrecht-Wiggans, R., Milgrom, P. and Weber, R. "Competitive Bidding and Proprietary Information". Journal of Mathematical Economics, 11(2):161-169, 1983.

[15] Farinha, L., and Santos, J. "Switching from Single to Multiple Bank Lending Relationships: Determinants and Implications". Journal of Financial Intermediation, 11(2):124-151, 2002.

[16] Gale, D., and Hellwig, M. "Incentive-compatible Debt Contracts: The One-Period Problem". Review of Economic Studies, 52(4):647-663, 1985.

[17] Gompers, P. "Optimal Investment, Monitoring, and the Staging of Venture Capital". Journal of Finance, 50(5):1461-1489, 1995.

[18] Hausch, D. "Multi-Object Auctions: Sequential vs. Simultaneous Sales". Management Science, 32(12):1599-1610, 1986.

[19] Hausch, D. "A Model of Sequential Auctions". Economics Letters, 26(3):227-233, 1988.

[20] Hauswald, R., and Marquez, R. "Competition and Strategic Information Acquisition in Credit Markets". Review of Financial Studies, 19(3):967-1000, 2006.

[21] Jappelli, T., and Pagano, M. "Information Sharing in Credit Markets". Journal of Finance, 43(5):1693-1718, 1993.

[22] Jappelli, T., and Pagano, M. "Information Sharing, Lending and Defaults: Cross-Country Evidence". Journal of Banking and Finance, 26(10):2017-2045, 2002.

[23] Krishna, V. Auction Theory. Academic Press, 2002.

[24] Lizzeri, A., and Persico, N. "Uniqueness and Existence of Equilibrium in Auctions with a Reserve Price". Games and Economic Behavior, 30(1):83-114, 2000.

[25] Miller, M. "Credit Reporting Systems around the Globe: The State of Art in Public Credit Registers and Private Credit Reporting Firms". In Miller, M., editor, Credit Reporting Systems and the International Economy, pages 25-80. MIT Press, 2003.

[26] Miwa, Y., and Ramseyer, M. "Does Relationship Banking Matter? The Myth of the Japanese Main Bank". Journal of Empirical Legal Studies, 2(2):261-302, 2005.

[27] Ortega-Reichert, A. "A Sequential Game with Information Flow". In P. Klemperer, editor, The Economic Theory of Auctions, chapter 6. Edward Elgar, 2000 (originally 1968).

[28] Petersen, M., and Rajan, R. "The Benefits of Lending Relationships: Evidence from Small Business Data". Journal of Finance, 49(1):3-37, 1994.

[29] Rajan, R. "Insiders and Outsiders: The Choice between Informed and Arm's-Length Debt". Journal of Finance, 47(4):191-212, 1992. 
[30] Riordan, M. "Competition and Bank Performance: a Theoretical Perspective". In Mayer, C., and Vives, X., editor, Capital Markets and Financial Intermediation, pages 328-343. Cambridge University Press, 1993.

[31] Schnitzer, M. "On the Role of Bank Competition for Corporate Finance and Corporate Control in Transition Economies". Journal of Institutional and Theoretical Economics, 155(1):22-46, 1999.

[32] Shaffer, S. "The Winner's Curse in Banking". Journal of Financial Intermediation, 7(4):359-392, 1998.

[33] Sharpe, S. "Asymmetric Information, Bank Lending and Implicit Contracts: A Stylized Model of Customer Relationships". Journal of Finance, 45(4):1069-1087, 1990.

[34] Skrzypacz, A., and Hopenhayn, H. "Tacit Collusion in Repeated Auctions". Journal of Economic Theory, 114(1):153-169, 2004.

[35] Stiglitz, J., and Weiss, A. "Incentive Effects of Terminations: Applications to Credit and Labor Markets". American Economic Review, 73(5):912-927, 1983.

[36] Townsend, R. "Optimal Contracts and Competitive Markets with Costly State Verification". Journal of Economic Theory, 21(2):265-293, 1979.

[37] von Thadden, E. "Long-Term Contracts, Short-Term Investment and Monitoring". Review of Economic Studies, 62(4):557-575, 1995.

[38] Weinstein, D., and Yafeh, Y. "On the Costs of a Bank-Centered Financial System: Evidence from the Changing Main Bank Relations in Japan". Journal of Finance, 53(2):635-672, 1998.

[39] Williamson, S. "Costly Monitoring, Loan Contracts, and Equilibrium Credit Rationing". Quarterly Journal of Economics, 102(1):135-145, 1987.

[40] Yafeh, Y., and Yosha, O. "Industrial Organization of Financial Systems and Strategic Use of Relationship Banking". European Financial Review, 5(1-2):63-78, 2001. 


\section{Appendix}

Proof of Lemma 1 We prove in the following steps. In the first step, we verify that the ranges of bids by Bank $W$ and Bank $L$ are identical. In the second step, we will show that the expected return from winning in the second competition is greater for Bank $L$ than for Bank $W$ if Bank $L$ plays the equilibrium strategy $R_{l}(l)$, which is monotone decreasing in its true private signal $l$. Based on the result, we show that the expected return from the second competition for Bank $W$ is zero by applying the Theorem 2 in Engelbrecht-Wiggans et al [14]. In the proof, we denote the domain of positive $g\left(R_{w}\right)$ by $\left[\underline{R}_{w}, \bar{R}_{w}\right]$ and the range of $R_{l}(l)$ by $\left[\underline{R}_{l}, \bar{R}_{l}\right]$.

Claim $1 \underline{R}_{l}=\underline{R}_{w}, \bar{R}_{l}=\bar{R}_{w}=V$.

(Proof) Assume $\underline{R}_{w}>\underline{R}_{l}$ to the contrary to the statement in the lemma, then Bank $L$ who bids $R_{l} \in\left[\underline{R}_{l}, \underline{R}_{w}\right]$ can increase its payoff without changing the probability to win by increasing its bid up to $\underline{R}_{w}$. $\underline{R}_{l}$ is not the lower bound of $R_{l}$. This is contradiction. If $\underline{R}_{w}<\underline{R}_{l}$ then the same reasoning can be applied to Bank $W$. Therefore, $\underline{R}_{w}=\underline{R}_{l}$ in the equilibrium.

Regarding the upper bound, assume $\bar{R}_{w}>\bar{R}_{l}$ to the contrary to the statement in the lemma, then Bank $W$ can increase its payoff without changing its winning probability by bunching all bids $R_{w} \in\left[\bar{R}_{l}, \bar{R}_{w}\right.$ ] at $V$ (note that Bank $L$ may not participate with a positive probability). But, then Bank $L$ can also increase its payoff without decreasing its winning probability by bidding a rate slightly lower than $V$ instead of bidding $\bar{R}_{l}$. $\bar{R}_{l}$ is not the upper bound of $R_{l}$. Contradiction. If $\bar{R}_{w}<\bar{R}_{l}$, we can show the contradiction in the same way. Therefore, $\bar{R}_{w}=\bar{R}_{l}$ at the equilibrium.

If a bank bids $\bar{R}_{w}=\bar{R}_{l}$ and wins, it is the only bidder in the market. Therefore, it quotes the monopolistic rate $V$.

Claim 2 At an interest rate $R=R_{l}(l)$, the expected return for Bank $L$ when it wins in the second competition is greater than that for Bank $W$ if Bank $L$ plays the monotone-decreasing strategy $R_{l}(l)$ where $l$ is its true private signal.

(Proof) The expected return for Bank $W$ conditional on that it wins in the second competition by bidding $R$ and it has signal $w$ is:

$$
\pi_{w w}=(R-I) \nu_{w w}-I\left(1-\nu_{w w}\right)
$$

where $\nu_{w w}=\frac{\nu_{w}(w) \frac{F(l \mid G)}{F(w \mid G)}}{\nu_{w}(w) \frac{F(l \mid G)}{F(w \mid G)}+\left(1-\nu_{w}(w)\right) \frac{F(l \mid B)}{F(w \mid B)}}$. The expected return for Bank $L$ conditional on that it wins in the second competition by bidding $R$ is:

$$
\pi_{l w}=(R-I) \nu_{l}(l, w)-I\left(1-\nu_{l}(l, w)\right) .
$$

From the reverse hazard rate dominance (4),

$$
\frac{\frac{1-\nu_{l}}{\nu_{l}}}{\frac{1-\nu_{w w}}{\nu_{w w}}} \leq \frac{f(l \mid B) / F(l \mid B)}{f(l \mid G) / F(l \mid G)}<1 .
$$

Therefore, $\pi_{l w}>\pi_{w w}$ if Bank $L$ plays the equilibrium strategy $R_{l}(l)$.

From these claims, we can prove that the return for Bank $W$ from the second competition is zero by the same logic as in Theorem 2 in Engelbrecht-Wiggans et al. [14]. Let us assume, to the contrary, that Bank $W$ can earn positive profit. Since any pure strategy assigned with a positive probability in a mixed strategy equilibrium must yield an identical return, Bank $W$ earns a positive profit when it bids $V$, and $q$ must be equal to 1 . If this is the case, Bank $L$ never bids $V$ since it can increase its return by slightly undercutting $V$ instead of bidding $V$ from Claim 2 (note the assumption that Bank $W$ wins if two bids tie at $V$ ). This is contradiction to Claim 1. Therefore, the return to Bank $W$ from the second competition is zero. 
Proof of Lemma 2 The RHS of Equation (9) is monotone decreasing in $s_{* 2}^{t l}$ from Assumption (1). Therefore, there exists a unique $s_{* 2}^{t l}$ if and only if the RHS is greater than the LHS at $\underline{s}$ and the RHS is less than the LHS at $\bar{s}$

$$
\frac{1-\gamma}{\gamma} \frac{f(\underline{s} \mid B)}{f(\underline{s} \mid G)} \frac{f(w \mid B)}{f(w \mid G)} \frac{F(\underline{s} \mid B)}{F(\underline{s} \mid G)}>\frac{V-I}{I}>\frac{1-\gamma}{\gamma} \frac{f(\bar{s} \mid B)}{f(\bar{s} \mid G)} \frac{f(w \mid B)}{f(w \mid G)} \frac{F(\bar{s} \mid B)}{F(\bar{s} \mid G)} .
$$

Since $F(\underline{s} \mid G)=F(\underline{s} \mid B)=0$ and $F(\bar{s} \mid G)=F(\bar{s} \mid B)=1$,

$$
\frac{1-\gamma}{\gamma}\left(\frac{f(\underline{s} \mid B)}{f(\underline{s} \mid G)}\right)^{2} \frac{f(w \mid B)}{f(w \mid G)}>\frac{V-I}{I}>\frac{1-\gamma}{\gamma} \frac{f(\bar{s} \mid B)}{f(\bar{s} \mid G)} \frac{f(w \mid B)}{f(w \mid G)}
$$

The first term comes from the L'Hopital's rule. If $s_{i} \rightarrow \bar{s}$, then $w \rightarrow \bar{s}$. From the assumption $(1)$, $\frac{f(w \mid B)}{f(w \mid G)}$ is decreasing in $w$ and the first order stochastic dominance (3) requires $\frac{f(\bar{s} \mid B)}{f(\bar{s} \mid G)}<1$ and $\frac{f(\underline{s} \mid B)}{f(\underline{s} \mid G)}>1$. Therefore, the next inequality implies the above inequality:

$$
\frac{1-\gamma}{\gamma}\left(\frac{f(\underline{s} \mid B)}{f(\underline{s} \mid G)}\right)^{2} \frac{f(\bar{s} \mid B)}{f(\bar{s} \mid G)}>\frac{V-I}{I}>\frac{1-\gamma}{\gamma}\left(\frac{f(\bar{s} \mid B)}{f(\bar{s} \mid G)}\right)^{2} .
$$

Proof of Proposition 1 From Lemma 1, the expected return for Bank $W$ is zero, i.e.,

$$
F\left(R_{l}^{-1}\left(R_{w}\right) \mid G\right)\left(R_{w}-I\right) \mu(w)-F\left(R_{l}^{-1}\left(R_{w}\right) \mid B\right) I(1-\mu(w))=0
$$

Bank $L$ chooses its bid by maximizing its expected return. The first order condition for the maximization with respect to $R_{l}$ is:

$$
\begin{gathered}
-g\left(R_{l}\right) q\left\{\left(R_{l}-I\right) \nu_{l}(l, w) f(w \mid G)-I\left(1-\nu_{l}(l, w)\right) f(w \mid B)\right\} \\
+\left(q\left(1-G\left(R_{l}\right)\right)+1-q\right)\left\{\nu_{l}(l, w) f(w \mid G)\right\}=0 .
\end{gathered}
$$

The bid function of Bank $L$ that satisfies Equation (51) is obtained by setting $R_{w}=R_{l}$ in Equation (51):

$$
R_{l}(l)=\left(1+\frac{F(l \mid B)}{F(l \mid G)} \frac{1-\mu(w)}{\mu(w)}\right) I
$$

Rearranging the first order condition (52) and substituting Equation (53) give:

$$
\frac{d\left\{q\left(1-G\left(R_{l}\right)\right)+1-q\right\}}{q\left(1-G\left(R_{l}\right)\right)+1-q}=\frac{d R_{l}}{\frac{F(l \mid B)}{F(l \mid G)} \frac{1-\mu(w)}{\mu(w)}\left(\frac{f(l \mid B) / F(l \mid B)}{f(l \mid G) / F(l \mid G)}-1\right)} .
$$

By differentiating Equation (53) with respect to $l$, we can rewrite $d R_{l}$ into:

$$
d R_{l}=\frac{F(l \mid B)}{F(l \mid G)}\left(\frac{f(l \mid B)}{F(l \mid B)}-\frac{f(l \mid G)}{F(l \mid G)}\right) \frac{1-\mu(w)}{\mu(w)} I d l .
$$

Substituting this equation into the FOC (52) yields:

$$
\frac{d\left\{q\left(1-G\left(R_{l}\right)\right)+1-q\right\}}{q\left(1-G\left(R_{l}\right)\right)+1-q}=\frac{f(l \mid G)}{F(l \mid G)} d l
$$

Integrating both side from $l$ to $w$ gives:

$$
\frac{q\left(1-G\left(R_{l}(l)\right)\right)+1-q}{q\left(1-G\left(R_{l}(w)\right)\right)+1-q}=\frac{F(l \mid G)}{F(w \mid G)} .
$$

The bid function of Bank $L$ is decreasing in $l . l$ is almost surely smaller than the private signal $w$ of Bank $W$. Therefore, a bid by Bank $L$ is almost surely higher than $R_{l}(w)$. Therefore, $G\left(R_{l}(w)\right)=0$ from Claim 1 in the proof of Lemma 1. Substituting this into the above expression gives:

$$
q\left(1-G\left(R_{l}(l)\right)\right)+1-q=\frac{F(l \mid G)}{F(w \mid G)} .
$$


The maximum bid by Bank $L$ is $V$. Therefore, $G(V)=1$ by Claim 1 in Lemma 1 . By setting $R_{l}=V$ in the previous expression, we obtain:

$$
q=1-\frac{F\left(s_{* 2}^{t w}(w) \mid G\right)}{F(w \mid G)},
$$

where $s_{* 2}^{t w}(w)$ is implicitly defined by $\frac{V-I}{I}=\frac{F\left(s_{* 2}^{t w} \mid B\right)}{F\left(s_{* 2}^{t w} \mid G\right)} \frac{1-\mu(w)}{\mu(w)}$. It is readily verified that a unique $s_{* 2}^{t w}$ exists under Assumption (10). The expected return for Bank $L$ from bidding $V$ is:

$$
(1-q)\left\{(V-I) \nu_{l}(l, w)-I\left(1-\nu_{l}(l, w)\right)\right\} .
$$

This return is zero at $s_{* 2}^{t l}(w)$, which is defined by Equation (9). $s_{* 2}^{t l}(w)$ also exists under Assumption (10). By Assumption (4), $s_{* 2}^{t l}$ is smaller than $s_{* 2}^{t w}$. If Bank $L$ 's private signal is between $s_{* 2}^{t l}$ and $s_{* 2}^{t w}$, then Bank $L$ bids the monopolistic rate $V$. The expected return for Bank $\mathrm{W}$ when it bids $V$ is zero regardless of such bunching on the side of Bank $L$ by the assumption that Bank $W$ wins when two bids tie. Substituting Equation (57) into Equation (56) and setting $R_{l}=R_{w}$ give:

$$
G\left(R_{w}\right)=\frac{F(w \mid G)-F\left(R_{l}^{-1}\left(R_{w}\right) \mid G\right)}{F(w \mid G)-F\left(s_{* 2}^{t w}(w) \mid G\right)} .
$$

Proof of Lemma 3 If nobody lent in the first competition, each bank knows that the private signal of the rival is less than $s_{* 1}^{t}$, which is derived in the proof of Lemma 4. Bank $i$ updates its subjective probability that the firm is good from $\mu\left(s_{i}\right)$ to :

$$
\nu_{0}\left(s_{i}, s_{* 1}^{t}\right)=\frac{\mu\left(s_{i}\right) F\left(s_{* 1}^{t} \mid G\right)}{\mu\left(s_{i}\right) F\left(s_{* 1}^{t} \mid G\right)+\left(1-\mu\left(s_{i}\right)\right) F\left(s_{* 1}^{t} \mid B\right)} .
$$

The expected return for Bank $i$ in the second competition when it gets a private signal $s_{i}$ but pretends to have a signal $y$ is:

$$
\pi_{2}=\frac{F(y \mid G)}{F\left(s_{* 1}^{t} \mid G\right)}\left(R_{2}\left(y ; s_{* 1}^{t}\right)-I\right) \nu_{0}\left(s_{i}, s_{* 1}^{t}\right)-\frac{F(y \mid B)}{F\left(s_{* 1}^{t} \mid B\right)} I\left(1-\nu_{0}\left(s_{i}, s_{* 1}^{t}\right)\right) .
$$

$\frac{F(y \mid v)}{F\left(s_{* 1}^{t} \mid v\right)}$ is the probability for the bank to win the competition given that rival private signal was less than $s_{* 1}^{t}$. By the revelation principle, we can focus on the equilibrium where $y=s_{i}$. The incentive compatibility condition is $d \pi_{2} / d y=0$ at $y=s_{i}$. It is easy to check that the sufficient condition for the existence of an equilibrium is satisfied by verifying that $d \pi_{2} / d y<0$ if $y>s_{i}$ and that $d \pi_{2} / d y>0$ if $y<s_{i}$ under the incentive compatibility condition. At this equilibrium, the screening threshold, $s_{* 2}$ is defined implicitly by:

$$
\frac{V-I}{I}=\frac{F\left(s_{* 2} \mid B\right)}{F\left(s_{* 2} \mid G\right)} \frac{1-\mu\left(s_{* 2}\right)}{\mu\left(s_{* 2}\right)} .
$$

$s_{* 2}$ is the point where each bank expects zero profit even if it bids the monopolistic interest rate, $V$. This is exactly the same as Equation (20) in Proposition 2 in the next section, which is the condition that defines the screening threshold in the first competition, $s_{* 1}^{t}$. Therefore, nobody bids in the second competition if nobody lends in the first competition.

Proof of Lemma 4 The expected return from bidding is Equation (15) or Equation (16) at $x=s_{i}$ under the incentive compatibility condition:

$$
\begin{aligned}
F\left(s_{i} \mid G\right)\left(R_{1}\left(s_{i}\right)-I\right) \mu\left(s_{i}\right)-F\left(s_{i} \mid B\right) I\left(1-\mu\left(s_{i}\right)\right) & \\
+ & \left(\int_{s_{i}}^{\bar{s}}\left(R_{l}\left(s_{i}, w\right)-I\right) \frac{F\left(s_{i} \mid G\right)}{F(w \mid G)} f(w \mid G) d w\right) \mu\left(s_{i}\right) \\
& -I\left(\int_{s_{i}}^{\bar{s}} \frac{F\left(s_{i} \mid G\right)}{F(w \mid G)} f(w \mid B) d w\right)\left(1-\mu\left(s_{i}\right)\right) .
\end{aligned}
$$

The expected return from not bidding in the first competition consists of three parts, 1) the rival bids and $s_{i}$ is higher than the rival private signal, 2 ) the rival bids and $s_{i}$ is lower than the private signal of the rival, and 3 ) the rival doesn't bid since its private signal is less than the threshold $s_{* 1}^{t}$. The first component is:

$$
\Psi_{1}=\int_{s_{* 1}^{t}}^{s_{i}}\left(R_{l}\left(s_{i}, w\right)-I\right) \frac{F\left(s_{i} \mid G\right)}{F(w \mid G)} f(w \mid G) d w \mu\left(s_{i}\right)-\int_{s_{* 1}^{t}}^{s_{i}} I \frac{F\left(s_{i} \mid G\right)}{F(w \mid G)} f(w \mid B) d w\left(1-\mu\left(s_{i}\right)\right) .
$$


In this case, the rival wins in the first competition although her private signal is less than the private signal of Bank $i$. Therefore, we take the expectation about the rival signal over the range in $\left[s_{* 1}^{t}, s_{i}\right]$. The second component is equal to the last two terms of Equation (61). The third component is equal to:

$$
\Psi_{2}=\max \left[F\left(s_{* 1}^{t} \mid G\right)(V-I) \mu\left(s_{i}\right)-F\left(s_{* 1}^{t} \mid B\right) I\left(1-\mu\left(s_{i}\right)\right), 0\right]
$$

If the rival doesn't bid since its private signal is less than $s_{* 1}^{t}$ and Bank $i$ doesn't bid, then the rival infers that the private signal of Bank $i$ is also less than $s_{* 1}^{t}$. Therefore, the rival doesn't bid in the second competition from the argument in Lemma 3. In this case, Bank $i$ wins for sure by bidding $V$ in the second competition. It will do so if the return from bidding $V$ is non-negative. From these expressions, the individual rationality condition is:

$$
F\left(s_{i} \mid G\right)\left(R_{1}\left(s_{i}\right)-I\right) \mu\left(s_{i}\right)-F\left(s_{i} \mid B\right) I\left(1-\mu\left(s_{i}\right)\right) \geq \Psi_{1}+\Psi_{2}
$$

Given these expressions, First, we will derive the $s_{* 1}^{t}$ where the inequality (62) holds with equality. Second, we will check the inequality strictly holds if $s_{i}>s_{* 1}^{t}$.

At $s_{i}=s_{* 1}^{t}$, Bank $i$ is the only participants when Bank $i$ wins. Therefore, Bank $i$ will bid the monopolistic rate $V$. The RHS of the inequality at $s_{i}=s_{* 1}^{t}$ is:

$$
F\left(s_{* 1}^{t} \mid G\right)(V-I) \mu\left(s_{* 1}^{t}\right)-F\left(s_{* 1}^{t} \mid B\right) I\left(1-\mu\left(s_{* 1}^{t}\right)\right) .
$$

If this is non-negative, the RHS of the inequality is the same as the LHS at $s_{i}=s_{* 1}^{t}$. If this is negative, then the RHS is zero. Therefore, the inequality (62) holds and the bank bids as long as the expression (63) is non-negative. The threshold $s_{* 1}^{t}$ is determined at the point where the RHS is zero, namely, at the point where the expression (63) is equal to zero. Rearranging this condition yields Equation (20) in Lemma $4 . s_{* 1}^{t}$ is uniquely determined since the RHS of Equation (20) is monotone decreasing in $s_{* 1}^{t}$ by Assumption (1). The existence can be verified by the same logic as in the proof of Lemma 2 under Assumption (10).

If $s_{i}>s_{* 1}^{t}$, the (LHS)-(RHS) of the inequality (62) after substituting Expressions (14) and (22) is:

$$
\begin{aligned}
& {[(\text { LHS }) \text {-(RHS) of Inequality }(62)] } \\
& \qquad \quad \int_{s_{* 1}^{t}}^{s_{i}} \frac{F(t \mid B)-F\left(s_{i} \mid B\right)}{F(t \mid G)} f(t \mid G) \frac{1-\mu(t)}{\mu(t)} d t I \mu\left(s_{i}\right) \\
&+\int_{s_{* 1}^{t}}^{s_{i}} \frac{F\left(s_{i} \mid G\right)}{F(t \mid G)} f(t \mid B) d t I\left(1-\mu\left(s_{i}\right)\right)+\left(F\left(s_{* 1}^{t} \mid B\right)-F\left(s_{i} \mid B\right)\right) I\left(1-\mu\left(s_{i}\right)\right) \\
& \geq \int_{s_{* 1}^{t}}^{s_{i}}\left\{\frac{F\left(s_{i} \mid G\right)}{F(t \mid G)}-\frac{F\left(s_{i} \mid B\right)}{F(t \mid B)}\right\} f(t \mid B) d t I\left(1-\mu\left(s_{i}\right)\right) \\
&>0 .
\end{aligned}
$$

The second inequality is derived by replacing $\frac{f(t \mid G)}{F(t \mid G)} \frac{1-\mu(t)}{\mu(t)}$ in the first term with $\frac{f(t \mid B)}{F(t \mid B)} \frac{1-\mu\left(s_{i}\right)}{\mu\left(s_{i}\right)}$, which is smaller than $\frac{f(t \mid G)}{F(t \mid G)} \frac{1-\mu(t)}{\mu(t)}$ by Assumption (1). The last inequality comes from the fact that $\frac{F\left(s_{i} \mid G\right)}{F\left(s_{i} \mid B\right)}$ is increasing in $s_{i}$ by Assumption (1).

Proof of Proposition 2 The calculation of the differential equation is straightforward. The monotone decreasing of $R_{1}\left(s_{i}\right)$ can also be verified by a simple algebra. Here, we verify that the problem satisfies the sufficient condition for the existence of the equilibrium.

If $x>s_{i}$, substituting the incentive compatibility condition of the rival with a private signal $x$ into the derivative of $\pi_{1}\left(s_{i}, x\right)$ with respect to $x$ gives:

$$
\frac{d \pi_{1}}{d x}=\mu\left(s_{i}\right) f(x \mid B) I \frac{1-\gamma}{\gamma} \frac{F(x \mid B)-F\left(s_{i} \mid B\right)}{F(x \mid G)}\left\{1-\frac{f\left(s_{i} \mid B\right)}{f\left(s_{i} \mid G\right)} \frac{F(x \mid G)-F\left(s_{i} \mid G\right)}{F(x \mid B)-F\left(s_{i} \mid B\right)}\right\}<0 .
$$

The last inequality comes from the fact that Assumption (1) implies:

$$
\frac{f\left(s_{i} \mid B\right)}{f\left(s_{i} \mid G\right)} \frac{F(x \mid G)-F\left(s_{i} \mid G\right)}{F(x \mid B)-F\left(s_{i} \mid B\right)}>1 .
$$

If $x<s_{i}$, substituting the incentive compatibility condition of the rival with a private signal $x$ into the derivative of $\pi_{1}\left(s_{i}, x\right)$ with respect to $x$ gives:

$$
\frac{d \pi_{1}}{d x}=\mu\left(s_{i}\right) f(x \mid B) I \frac{1-\gamma}{\gamma}\left\{\frac{f(x \mid B)}{f(x \mid G)}-\frac{f\left(s_{i} \mid B\right)}{f\left(s_{i} \mid G\right)}\right\}>0 .
$$

The sufficient condition is satisfied.

Theorem 1 in Lizzeri and Persico [24], which shows the uniqueness of the monotone strategy equilibrium in sealed-bid auctions with a reserve price, is readily applicable to the auction in the first competition. 
Proof of Proposition 3 The probability that no banks lend in the first competition is $1-F\left(s_{* 1}^{t} \mid \text { type }\right)^{2}$. The probability that Bank $W$ doesn't participate in the second competition is $F\left(s_{* 2}^{t w} \mid G\right) / F(w \mid G)$ from Equation (11). The probability that Bank $L$ doesn't participate in the second competition is $F\left(s_{* 2}^{t l} \mid\right.$ type $) / F(w \mid$ type $)$ from the result of Proposition 1 given $w$. Therefore, the probability that at least a bank lends is $1-F^{2}\left(s_{* 1}^{t} \mid\right.$ type $)$ in the first competition and $1-\frac{F\left(s_{* 2}^{t w} \mid t y p e\right)}{F(w \mid t y p e)} \frac{F\left(s_{* 2}^{t w} \mid G\right)}{F(w \mid G)}$ in the second competition. Therefore, the ex-ante social welfare of two sequential loans to a firm is:

$$
\begin{aligned}
& \gamma(V-I)\left(1-F^{2}\left(s_{* 1}^{t} \mid G\right)\right)-(1-\gamma) I\left(1-F^{2}\left(s_{* 1}^{t} \mid B\right)\right) \\
& \quad+\gamma \int_{s_{* 1}^{t}}^{\bar{s}}(V-I)\left(1-\frac{F\left(s_{* 2}^{t l}(w) \mid G\right)}{F(w \mid G)} \frac{F\left(s_{* 2}^{t w}(w) \mid G\right)}{F(w \mid G)}\right) 2 f(w \mid G) F(w \mid G) d w \\
& \quad-(1-\gamma) \int_{s_{* 1}^{t}}^{\bar{s}} I\left(1-\frac{F\left(s_{* 2}^{t l}(w) \mid B\right)}{F(w \mid B)} \frac{F\left(s_{* 2}^{t w}(w) \mid G\right)}{F(w \mid G)}\right) 2 f(w \mid B) F(w \mid B) d w .
\end{aligned}
$$

The first two terms are the ex-ante social return from the first competition conditional on the public information at Date 0. The last two terms are the ex-ante social return from the second competition. In these terms, we need to calculate the expected value of $w$, the private signal of a potential winner in the first competition.

The first order condition to maximize the social welfare with respect to $s_{* 1}^{t}$ is:

$$
\frac{V-I}{I}=\frac{F\left(s_{* 1}^{t} \mid B\right)}{F\left(s_{* 1}^{t} \mid G\right)} \frac{1-\mu\left(s_{* 1}^{t}\right)}{\mu\left(s_{* 1}^{t}\right)}-A
$$

where

$$
\begin{aligned}
A= & \frac{V-I}{I}\left(1-\frac{F\left(s_{* 2}^{t l}\left(s_{* 1}^{t}\right) \mid G\right)}{F\left(s_{* 1}^{t} \mid G\right)} \frac{F\left(s_{* 2}^{t w}\left(s_{* 1}^{t}\right) \mid G\right)}{F\left(s_{* 1}^{t} \mid G\right)}\right) \\
& -\left(1-\frac{F\left(s_{* 2}^{t l}\left(s_{* 1}^{t}\right) \mid B\right)}{F\left(s_{* 1}^{t} \mid B\right)} \frac{F\left(s_{* 2}^{t w}\left(s_{* 1}^{t}\right) \mid G\right)}{F\left(s_{* 1}^{t} \mid G\right)}\right) \frac{F\left(s_{* 1}^{t} \mid B\right)}{F\left(s_{* 1}^{t} \mid G\right)} \frac{1-\mu\left(s_{* 1}^{t}\right)}{\mu\left(s_{* 1}^{t}\right)} .
\end{aligned}
$$

$A$ is positive if $s_{* 1}^{t}$ is in the neighborhood of the competitive screening, which is defined by Equation (20), since $s_{* 2}^{t l}\left(s_{* 1}^{t}\right)<s_{* 2}^{t w}\left(s_{* 1}^{t}\right)=s_{* 1}^{t}$ and $\frac{d}{d s} \frac{F(s \mid B)}{F(s \mid G)}<0$ by Assumption (1). This implies that the competitive screening in the first competition is severer than the ex-ante second-best level.

The second order condition is verified by rearranging the derivative of the ex ante welfare (66) with respect to $s_{* 1}$, as follows:

$$
\begin{aligned}
& -(1-\gamma) f\left(s_{* 1}^{t} \mid B\right) I\left[F\left(s_{* 1}^{t} \mid B\right)\left(\frac{V-I}{I} \frac{\gamma}{1-\gamma} \frac{f\left(s_{* 1}^{t} \mid G\right)}{f\left(s_{* 1}^{t} \mid B\right)} \frac{F\left(s_{* 1}^{t} \mid G\right)}{F\left(s_{* 1}^{t} \mid B\right)}-1\right)+\left(1-\frac{F\left(s_{* 2}^{t l} \mid B\right)}{F\left(s_{* 1}^{t} \mid B\right)}\right)\right. \\
& \left.\times\left(\frac{V-I}{I} \frac{\gamma}{1-\gamma} \frac{f\left(s_{* 1}^{t} \mid G\right)}{f\left(s_{* 1}^{t} \mid B\right)} \frac{F\left(s_{* 1}^{t} \mid G\right)}{F\left(s_{* 1}^{t} \mid B\right)} \frac{F\left(s_{* 1}^{t} \mid B\right) F\left(s_{* 1}^{t} \mid G\right)-\frac{F\left(s_{* 1}^{t} \mid B\right)}{F\left(s_{*}^{t} \mid G\right)} F\left(s_{* 2}^{t l} \mid G\right) F\left(s_{* 2}^{t w} \mid G\right)}{F\left(s_{* 1}^{t} \mid B\right) F\left(s_{* 1}^{t} \mid G\right)-F\left(s_{* 2}^{t l} \mid B\right) F\left(s_{* 2}^{t w} \mid G\right)}-1\right)\right] .
\end{aligned}
$$

By Assumption (1), each component in the bracket is increasing in $s_{* 1}^{t}$. Therefore, if $s_{* 1}^{t}$ is greater than the level determined by the first order condition, the welfare is decreasing in $s_{* 1}^{t}$. If $s_{* 1}^{t}$ is smaller than that, the welfare is increasing in $s_{* 1}^{t}$. Thus, the screening level determined by the first order condition (67) is the social optimum.

Proof of Proposition 5 In the first step, we verify that the ranges of bids by Bank $W$ and Bank $L$, which are denoted by $\left[\underline{R}_{w}, \bar{R}_{w}\right]$ and $\left[\underline{R}_{l}, \bar{R}_{l}\right]$, respectively, are almost surely identical. Based on the result, we derive the equilibrium strategy.

Claim $3 \underline{R}_{l}=\underline{R}_{w}$, sup $R_{l}=\bar{R}_{w}=V$ in the 2nd competition for relationship banking.

(Proof) Assume $\underline{R}_{w}>\underline{R}_{l}$ to the contrary to the statement in the claim, then Bank $L$ that bids $R_{l} \in\left[\underline{R}_{l}, \underline{R}_{w}\right]$ can increase its payoff without changing the probability to win by increasing the bid up to $\underline{R}_{w}$. $\underline{R}_{l}$ is not the lower bound of $R_{l}$. This is contradiction. If $\underline{R}_{w}<\underline{R}_{l}$ then the same reasoning can be applied to Bank $W$. Therefore, $\underline{R}_{w}=\underline{R}_{l}$ in the equilibrium.

Assume that $\bar{R}_{w} \leq \bar{R}_{l}$ to the contrary to the statement in the claim, then Bank $L$ gets negative return for sure if it bids $R_{l} \in\left[\bar{R}_{w}, \bar{R}_{l}\right]$. Therefore, it never bids this range of rates, i.e., $\bar{R}_{w}>R_{l}$. At $\bar{R}_{w}$, Bank $W$ is the only bidder, so it bids the monopolistic rate, $\bar{R}_{w}=V$.

If $\sup R_{l}<\bar{R}_{w}=V$, then Bank $W$ can increase its payoff without decreasing its winning probability by bunching all bids $R_{w} \in\left[\sup R_{l}, V\right]$ at $V$. But, then Bank $L$ can also increase its payoff without decreasing its 
winning probability by bidding a rate slightly lower than $V$ instead of bidding $R_{l}<\sup R_{l}$. $\sup R_{l}$ is not the upper bound of $R_{l}$. Contradiction. Therefore, $\sup R_{l}=\bar{R}_{w}$ in the equilibrium.

Based on Claim 3, we derive the equilibrium bid in the second competition given that the winner's private signal is equal to $w$, and that Bank $W$ wins at $R_{1}(x)$. The first order condition and the participation constraint for Bank $L$ are, respectively:

$$
\begin{aligned}
& \left(\frac{d}{d R_{l}}\left(1-H\left(R_{l}\right)\right)\right)\left(R_{l}-I\right) \nu_{l}(l, w)-\left(1-H\left(R_{l}\right)\right) \nu_{l}(l, w)=0, \\
& \left(1-H\left(R_{l}\right)\right)\left(R_{l}-I\right) \nu_{l}(l, w)-I\left(1-\nu_{l}(l, w)\right) \geq 0 .
\end{aligned}
$$

Under the first order condition (69), the expected return for Bank $L$ is increasing in $l$. Therefore, the condition (70) is simplified into the next statement:

$$
\begin{aligned}
& \text { Bank } L \text { participates } \Longleftrightarrow l>s_{* 2}^{r l}, \\
& \text { where } s_{* 2}^{r l} \text { is implicitly defined by: } \frac{V-I}{I}=\frac{1-\nu_{l}\left(s_{* 2}^{r l}, w\right)}{\nu_{l}\left(s_{* 2}^{r l}, w\right)} \frac{1}{1-H(V)} .
\end{aligned}
$$

By bidding $V$, Bank $W$ expects to earn:

$$
\frac{F\left(s_{* 2}^{r l}(w) \mid G\right)}{F(x \mid G)}(V-I)
$$

This is the expected return to Bank $W$ from participating in the second competition since the return from each pure strategy that is assigned with a positive probability in a mixed strategy must be identical in the equilibrium. The bid by Bank $L$ that is consistent with this return is:

$$
R_{l}(l, w)-I=\frac{F\left(s_{* 2}^{r l}(w) \mid G\right)}{F(l \mid G)}(V-I) .
$$

In case that $l \geq w$, the optimal bid of Bank $L$ is equal to $R_{l}(w, w)$ from the first order condition (69). Substitution this function into the first order condition (69) and solving the resulting differential equation yield:

$$
1-H\left(R_{w}\right)=\frac{F\left(R_{l}^{-1}\left(R_{w} ; w\right) \mid G\right)}{F(w \mid G)} .
$$

At $R_{w}=V, 1-H(V)=\frac{F\left(s_{* 2}^{r l}(w) \mid G\right)}{F(w \mid G)}$. Substituting this equation into Equation (71) gives the result in Proposition 5 .

Proof of Proposition 6 First-order and sufficient conditions. First, we derive the first order condition for the symmetric equilibrium bid of Bank $i$ in the first competition. Since $w$ is observable to the rival after the first competition, each bank doesn't have an incentive to deviate from the choice rule, which is derived in Section 4.2, when it wins the first competition. If $s_{i} \leq s_{r}$, the derivative of its expected return $\pi_{1}\left(x, s_{i}\right)$ with respect to $x$ has three forms according to the three cases, which are listed in Section 4.3. If $s_{r} \geq x>s_{i}$, then the rival will undertake transaction banking when it wins and its private signal is greater than $s_{r}$, or undertake relationship banking otherwise. Therefore, the derivative is:

$$
\begin{aligned}
\frac{d \pi_{1}\left(x, s_{i}\right)}{d x} & =f(x \mid G)\left(R_{1}(x)-I\right) \mu\left(s_{i}\right)+F(x \mid G) \frac{d R_{1}(x)}{d x} \mu\left(s_{i}\right) \\
& -c\left\{f(x \mid G) \mu\left(s_{i}\right)+f(x \mid B)\left(1-\mu\left(s_{i}\right)\right\}-\frac{F\left(s_{* 2}^{r l}(x) \mid G\right)}{F(x \mid G)}(V-I) f(x \mid G) \mu\left(s_{i}\right) .\right.
\end{aligned}
$$

If $x \geq s_{r}>s_{i}$, the rival will undertake transaction banking when it wins. Therefore, the derivative is:

$$
\begin{aligned}
& \frac{d \pi_{1}\left(x, s_{i}\right)}{d x}=f(x \mid G)\left(R_{1}(x)-I\right) \mu\left(s_{i}\right)+F(x \mid G) \frac{d R_{1}(x)}{d x} \mu\left(s_{i}\right)-f(x \mid B) I\left(1-\mu\left(s_{i}\right)\right) \\
& \quad-c\left\{f(x \mid G) \mu\left(s_{i}\right)+f(x \mid B)\left(1-\mu\left(s_{i}\right)\right\}-\left(R_{l}\left(s_{i}, x\right)-I\right) \frac{F\left(s_{i} \mid G\right)}{F(x \mid G)} f(x \mid G) \mu\left(s_{i}\right)+\frac{F\left(s_{i} \mid G\right)}{F(x \mid G)} f(x \mid B) I\left(1-\mu\left(s_{i}\right)\right) .\right.
\end{aligned}
$$

If $s_{r} \geq s_{i} \geq x$, then the rival will undertake transaction banking when it wins and its private signal is greater than $s_{r}$, or undertake relationship banking otherwise. Therefore, the derivative is:

$$
\begin{aligned}
\frac{d \pi_{1}\left(x, s_{i}\right)}{d x} & =f(x \mid G)\left(R_{1}(x)-I\right) \mu\left(s_{i}\right)+F(x \mid G) \frac{d R_{1}(x)}{d x} \mu\left(s_{i}\right) \\
& -c\left\{f(x \mid G) \mu\left(s_{i}\right)+f(x \mid B)\left(1-\mu\left(s_{i}\right)\right\}-\left(R_{l}(x, x)-I\right) f(x \mid G) \mu\left(s_{i}\right) .\right.
\end{aligned}
$$


If $s_{i} \leq s_{r}$, clearly the incentive compatibility condition for Bank $i$ is:

$$
\begin{aligned}
& f\left(s_{i} \mid G\right)\left(R_{1}\left(s_{i}\right)-I\right) \mu\left(s_{i}\right)+F\left(s_{i} \mid G\right) \frac{d R_{1}\left(s_{i}\right)}{d s_{i}} \mu\left(s_{i}\right) \\
& \quad-c\left\{f\left(s_{i} \mid G\right) \mu\left(s_{i}\right)+f\left(s_{i} \mid B\right)\left(1-\mu\left(s_{i}\right)\right\}-\frac{F\left(s_{* 2}^{r l}\left(s_{i}\right) \mid G\right)}{F\left(s_{i} \mid V\right)}(V-I) \mu\left(s_{i}\right) f\left(s_{i} \mid G\right)=0 .\right.
\end{aligned}
$$

If $x \leq s_{r}$, then the rival with a private signal $x$ chooses its bid according to the incentive compatibility condition under relationship banking (75). If $x>s_{r}$, then the rival with a private signal $x$ chooses its bid according to the incentive compatibility condition under transaction banking (19). By substituting these incentive compatibility condition for the rival with a private signal $x$ into the derivative $\frac{d \pi_{1}\left(x, s_{i}\right)}{d x}$, we can show that:

$$
\begin{array}{llll}
\frac{d \pi_{1}\left(x, s_{i}\right)}{d x}>0 & \text { if } & x<s_{i}, \\
\frac{d \pi_{1}\left(x, s_{i}\right)}{d x}=0 & \text { if } & x=s_{i}, \\
\frac{d \pi_{1}\left(x, s_{i}\right)}{d x}<0 & \text { if } & x>s_{i} .
\end{array}
$$

in each case of $s_{i} \leq s_{r}$ and $s_{i}>s_{r}$, respectively. Therefore, the incentive compatibility condition (75) is sufficient. Likewise, we can show that the incentive compatibility condition when Bank $i$ undertakes transaction banking (19) is sufficient.

The screening threshold in the first competition under relationship banking, $s_{* 1}^{r}$. The expected return when $s_{i}<s_{r}$ and Bank $i$ participates in the first competition is:

$$
\begin{aligned}
& \pi_{1}\left(s_{i} ; s_{i}\right)=F\left(s_{i} \mid G\right)\left(R_{1}\left(s_{i}\right)-I\right) \mu\left(s_{i}\right)-F\left(s_{i} \mid B\right)\left(1-\mu\left(s_{i}\right)\right) \\
& \quad+F\left(s_{* 2}^{r l}\left(s_{i}\right) \mid G\right)(V-I) \mu\left(s_{i}\right)-c\left\{F\left(s_{i} \mid G\right) \mu\left(s_{i}\right)+F\left(s_{i} \mid B\right)\left(1-\mu\left(s_{i}\right)\right)\right\} \\
& \quad+\int_{s_{r}}^{\bar{s}} \frac{F\left(s_{i} \mid G\right)}{F(w \mid G)}\left\{\left(R_{l}\left(s_{i}, w\right)-I\right) f(w \mid G) \mu\left(s_{i}\right)-I f(w \mid B)\left(1-\mu\left(s_{i}\right)\right)\right\} d w \\
& \quad+\int_{s_{i}}^{s_{r}}\left\{\frac{F\left(s_{* 2}^{r l}(w) \mid G\right)}{F(w \mid G)}(V-I) f(w \mid G) \mu\left(s_{i}\right)-I f(w \mid B)\left(1-\mu\left(s_{i}\right)\right)\right\} d w
\end{aligned}
$$

The expected return for Bank $i$ when $s_{i}<s_{r}$ and it doesn't bid is the sum of the next four components. 1) If the winner's private signal $w$ is greater than $s_{r}$, then the expected return is the third line in Equation (76). 2) If $w \in\left[s_{r}, s_{i}\right)$, then the winner chooses relationship banking. The return in this case is the same as the last line in Equation (76). 3) If $w \leq s_{i}<s_{r}$, then Bank $i$ wins and gets a positive expected return with probability one by bidding $R_{l}(w, w)$. The expected return in this case is:

$$
\int_{s_{* 1}^{r}}^{s_{i}} \frac{F\left(s_{* 2}^{r l}(w) \mid G\right)}{F(w \mid G)}(V-I) f(w \mid G) d w \mu\left(s_{i}\right)-\left(F\left(s_{i} \mid B\right)-F\left(s_{* 1}^{r} \mid B\right)\right) I\left(1-\mu\left(s_{i}\right)\right) .
$$

4) If nobody bids, the rival infers that Bank $i$ also has a private signal lower than the threshold $s_{* 1}^{r}$. The rival doesn't bid in the second competition from the same logic as in the analysis in Case 2 in the second competition of transaction banking. Therefore, Bank $i$ bids the monopolistic rate $V$ in the second competition as long as it yields a positive expected return. The expected return in this case is:

$$
\max \left[0, F\left(s_{* 1}^{r} \mid G\right)(V-I) \mu\left(s_{i}\right)-F\left(s_{* 1}^{r} \mid B\right) I\left(1-\mu\left(s_{i}\right)\right)\right] .
$$

$s_{* 1}^{r}$ is determined at the point where the return from participating is equal to the return from not participating, which is defined by Equation (49). Under Assumption (1), the right hand side of Equation (49) is monotone decreasing in $s_{* 1}^{r}$. Moreover, the right hand side of Equation (49) goes to $+\infty$ as $s_{i}$ goes to $\underline{s}$. Therefore, the second inequality in Assumption (10) assures the existence of the unique $s_{* 1}^{r}$.

At $s_{i}=s_{* 1}^{r}$, Bank $i$ bids $V$ since it is the only participant. We can derive the perfect Bayesian equilibrium bid function $R_{1}\left(s_{i}\right)=R_{1}^{r}\left(s_{i}\right)$ when $s_{i}<s_{r}$ by solving the differential equation (75) under the boundary condition that $R_{1}^{r}\left(s_{* 1}^{r}\right)=V . R_{1}\left(s_{i}\right)=R_{1}^{t}\left(s_{i}\right)$ when $s_{i} \geq s_{r}$ can be derived by solving the differential equation (19) under the boundary condition that $R_{1}^{t}\left(s_{r}\right)=R_{1}^{r}\left(s_{r}\right)$ at $s_{i}=s_{r}$. The last condition comes from the reasoning that the bid by Bank $i$ in the first competition must be identical when it is indifferent between transaction banking and relationship banking. 
Proof of Proposition 7 Since Bank $W$ undertakes relationship banking if $w \leq s_{r}$ and it undertakes transaction banking otherwise, the ex ante social welfare under possible relationship banking is:

$$
\begin{gathered}
\gamma(V-I)\left(1-F^{2}\left(s_{* 1}^{t} \mid G\right)\right)-(1-\gamma) I\left(1-F^{2}\left(s_{* 1}^{t} \mid B\right)\right) \\
+\gamma \int_{s_{r}}^{\bar{s}}(V-I)\left(1-\frac{F\left(s_{* 2}^{t l}(w) \mid G\right)}{F(w \mid G)} \frac{F\left(s_{* 2}^{t w}(w) \mid G\right)}{F(w \mid G)}\right) 2 f(w \mid G) F(w \mid G) d w \\
-(1-\gamma) \int_{s_{r}}^{\bar{s}} I\left(1-\frac{F\left(s_{* 2}^{t l}(w) \mid B\right)}{F(w \mid B)} \frac{F\left(s_{* 2}^{t w}(w) \mid G\right)}{F(w \mid G)}\right) 2 f(w \mid B) F(w \mid B) d w \\
+\gamma\left(F^{2}\left(s_{r} \mid G\right)-F^{2}\left(s_{* 1}^{r} \mid G\right)\right)(V-I) \\
-\left\{\gamma\left(F^{2}\left(s_{r} \mid G\right)-F^{2}\left(s_{* 1}^{r} \mid G\right)\right)+(1-\gamma)\left(F^{2}\left(s_{r} \mid B\right)-F^{2}\left(s_{* 1}^{r} \mid B\right)\right)\right\} c \\
-(1-\gamma) \int_{s_{* 1}^{r}}^{s_{r}}\left(1-\frac{F\left(s_{* 2}^{r l}(w) \mid B\right)}{F(w \mid B)}\right) 2 f(w \mid B) F(w \mid B) I d w .
\end{gathered}
$$

The first statement in the proposition is derived by comparing Equation (20), Equation (49), and the first order condition with respect to $s_{* 1}^{r}$ to maximize the above expression, Equation (50). The second statement can be readily verified by calculating the difference between the welfare under transaction banking (66), and that under relationship banking (77) at $s_{* 1}^{r}=s_{* 1}^{t}$, taking into account the definition of $s_{* 2}^{r l}$, Equation (40). 